\title{
Comparative Studies on
} Multi-Component Pharmacokinetics of Polygonum multiflorum Thunb Extract After Oral Administration in Different Rat Models

\author{
Ninghui Ma ${ }^{1}$, Yong Zhang ${ }^{2}$, Liyan Sun ${ }^{1}$, Yuan Zhao ${ }^{3 *}$, Yue Ding ${ }^{1,2 *}$ and Tong Zhang ${ }^{1,2}$ \\ ${ }^{1}$ School of Pharmacy, Shanghai University of Traditional Chinese Medicine, Shanghai, China, ${ }^{2}$ Experiment Center of Teaching and \\ Learning, Shanghai University of Traditional Chinese Medicine, Shanghai, China, ${ }^{3}$ Experiment Center for Science and Technology, \\ Shanghai University of Traditional Chines Medicine, Shanghai, China
}

OPEN ACCESS

Edited by:

Alejandro Urzua,

University of Santiago, Chile

Reviewed by:

Yun Xia Li,

Chengdu University of Traditional

Chinese Medicine, China

Zhao-Fang Bai,

302 Military Hospital of China, China

Zhaoyan Zhang,

Beijing University of Technology,

China

*Correspondence:

Yue Ding

dingyue-2001@hotmail.com

Yuan Zhao

cmx_1@126.com

Specialty section: This article was submitted to

Ethnopharmacology,

a section of the journal

Frontiers in Pharmacology

Received: 02 February 2021 Accepted: 31 May 2021

Published: 17 June 2021

Citation:

Ma N, Zhang Y, Sun L, Zhao Y, Ding Y and Zhang T (2021) Comparative

Studies on Multi-Component Pharmacokinetics of Polygonum multiflorum Thunb Extract After Oral Administration in Different Rat Models.

Front. Pharmacol. 12:655332. doi: 10.3389/fphar.2021.655332
The clinical use of Polygonum multiflorum Thunb (PM) has been restricted or banned in many countries, due to its hepatotoxic adverse effects. Its toxicity research has become a hot topic. So far, the pharmacokinetic studies of PM, focusing on prototype compounds such as 2,3,5,4'-tetrahydroxystilbene-2-O- $\beta$-D-glucoside (TSG), emodin, and physcion, have been considered the main basis of pharmacodynamic material or of toxic effect. However, pharmacokinetic studies of its phase II metabolites have not yet been reported, mainly because the quantifications of such metabolites are difficult to do without the reference substance. In addition, pharmacokinetic studies on different pathological models treated with PM have also not been reported. On the other hand, toxic effects of PM have been reported in patients diagnosed with different liver pathologies. In the present work, a simultaneous quantitation method for eight prototypes components of PM and their five phase II metabolites has been performed by ultra-high performance liquid chromatography-tandem mass spectrometry (UPLC-MS/MS) and used for the pharmacokinetic study of PM in two different liver pathological models in rats (normal, alpha-naphthylisothiocyanate (ANIT), and carbon tetrachloride $\left.\left(\mathrm{CCl}_{4}\right)\right)$. The results showed that the main blood-entering components of PM are TSG, emodin, physcion, emodin-8-O$\beta$-D-glucoside (E-Glu), physcion-8-O- $\beta-D-g l u c o s i d e ~(P-G l u)$, aloe-emodin, gallic acid, resveratrol and catechin, among which TSG, emodin, and catechin were primary metabolized in phase II, while resveratrol was converted to all phase II metabolites, and the others were metabolized as drug prototypes. Meanwhile, their pharmacokinetic parameters in the different models also exhibited significant differences. For instance, the AUC $(0-\infty)$ values of the TSG prototype and its phase II metabolites were higher in the ANIT group, followed by $\mathrm{CCl}_{4}$ group and the normal group, while the AUC $(0-\infty)$ values of the emodin prototype and its phase II metabolites were

Abbreviations: PM, Polygonum multiflorum Thunb; AE-PM, alcohol extracts of Polygonum multiflorum Thunb; UPLC-MS/ MS, ultra-high performance liquid chromatography-tandem mass spectrometry; TSG, 2,3,5,4'-tetrahydroxystilbene-2-O- $\beta$-Dglucoside; E-Glu, emodin-8-O- $\beta$-D-glucoside; P-Glu, physcion-8-O- $\beta$-D-glucoside; ANIT, alpha-naphthylisothiocyanate; $\mathrm{CCl}_{4}$, Carbon tetrachloride. 
higher in the $\mathrm{CCl}_{4}$ group. To further illustrate the reasons for the pharmacokinetic differences, bilirubin metabolizing enzymes and transporters in the liver were measured, and the correlations with the AUC of the main compounds were analyzed. TSG and aloe-emodin have significant negative correlations with UGT1A1, BSEP, OATP1A4, OCT1, NTCP, MRP2 and MDR1 $(p<0.01)$. These data suggest that when the expression of metabolic enzymes and transporters in the liver is inhibited, the exposure levels of some components of PM might be promoted in vivo.

Keywords: ANIT, CCI4, pharmacokinetics, bilirubin metabolism enzyme, metabolic transporter, polygonum multiflorum thunb

\section{INTRODUCTION}

Polygonum multiflorum Thunb (PM) is a traditional tonic Chinese medicine used to fortify the liver and kidneys, benefit the essence and blood, and darken the hair. Also, it has been widely used in clinical and health care products (Medicine SAoTC, 1999; Commission CP, 2020). However, in recent years, there were increasing reports of adverse effects to the liver caused by PM, mainly manifested as hyperbilirubinemia, with classical clinical signs, such as yellow staining of the skin and sclera, and deepening of the urine color. Warning information on the hepatic injury promoted by PM has been released by Canadian, British and Australian as well as Chinese pharmacovigilance authorities (Zhang et al., 2009; LI C, 2015). We have reviewed the clinical literature reports on hepatic injury or hepatotoxic adverse reactions of PM in the past decade, and found that there are about 70 articles worldwide containing about 800 cases of adverse reactions of PM (Ma et al., 2020). The confusing use of crude and processed PM and large doses over the long term are the main factors causing adverse reactions in the liver caused by PM. Besides, some idiosyncratic susceptible populations should also receive more attention. There are two main mechanisms associated with the liver injury induced by PM. Firstly, genetic factors may predispose to the aggravation of adverse effects resulting from exposure to $\mathrm{PM}$, for example carrying the HLA-B ${ }^{\star} 35: 01$ allele (Li et al., 2019) and weak CYP450 activity in the body (Li et al., 2017). And secondly, PM may interfere with the expression of key proteins in the regulation of liver functions, such as the bilirubin metabolizing enzyme UGT1A1 expression inhibition (Qi et al., 2015; Wang et al., 2017; Qi et al., 2019), and the peroxisome proliferatoractivated receptor- $\gamma$ (PPAR- $\gamma$ ) inhibition (Lan-zhi et al., 2017).

Pharmacokinetic studies are an essential part of exploring the mechanisms related to liver injury caused by PM, taking into account the principal components (e.g., TSG and emodin) (Lv et al., 2011a; Lin et al., 2015a; Ma et al., 2015). The metabolites of these components in PM have been identified in some studies (Lin et al., 2015b; Ma et al., 2015; Zhang et al., 2018a; Zhang et al., 2018b). It is worth to mention that TSG, emodin, and physcion are mainly metabolized in phase II (glucuronidation and sulfation). However, the pharmacokinetic parameters of these metabolites have not been studied in the above reports, as the reference substances were hard to obtain. On that basis, we selected $\beta$-glucuronidase and sulfate esterase to hydrolyze the glucuronidated and sulfated combinations of plasma samples into the prototype drug. Then we measured the prototype drug indirectly to determine the phase II metabolites concentrations. It could help us to complete the gaps of pharmacokinetic studies for these phase II metabolites. Besides, liver injury caused by PM is often accompanied by an increase in the blood bilirubin levels, and the phase II metabolism of the above components is similar to the metabolism of bilirubin glucuronidation. It is hypothesized that the bilirubin metabolizing enzymes and transporters (e.g., UGT1A1, MRP2, BSEP, MDR1, and NTCP), which play important roles in the metabolism of bilirubin (Ransil et al., 1992; Faber et al., 2003; Otsuka et al., 2005; Hagenbuch, 2007; Nies et al., 2008; Hoekstra et al., 2013), would affect the pharmacokinetic behavior of the main components in PM. The liver injury profile induced by PM could be determined by the hepatocellular injury $(R \geq 5)$ and cholestatic/mixed liver injury $(R<5)$ according to the Roussel Uclaf Causality Assessment Method (RUCAM), with a high proportion of hepatocellular injury in clinical cases (Jung et al., 2011; Dong et al., 2014; Byeon et al., 2019; Liu et al., 2019; Wang et al., 2019). Bile duct ligation and drug induction are the most commonly used methods to simulate cholestasis in laboratory studies, with ANIT being the most common. $\mathrm{CCl}_{4}$ is also experimentally used as a common inducer of liver injury, and its induced pathological changes are primarily manifested as hepatocyte degeneration and necrosis. It is also described that UGT1A1 enzyme activity is impaired in ANIT and $\mathrm{CCl}_{4}$ intoxicated rats, similar to PM-induced liver injury (Sasaki et al., 1990; Chang et al., 2005; Zhao et al., 2007; Yang et al., 2008). Herein, it is the first work to investigate the different pharmacokinetic behavior of the PM components in the ANIT and $\mathrm{CCl}_{4}$-induced liver injury models in rats and the correlation between the exposure characteristics of the active ingredients in PM and the expression levels of liver metabolizing enzymes and transporters, which have given us some clues to illustrate the toxicity of PM in different rat models with liver injury.

\section{MATERIALS AND METHODS}

\section{Chemicals and Reagents}

Polygonum multiflorum Thunb (PM) supplied by Shanghai Kangqiao TCM, Co., Ltd (Shanghai, China). The standards $2,3,5,4^{\prime}$-tetrahydroxystilbene-2-O- $\beta$-D-glucoside (TSG), 


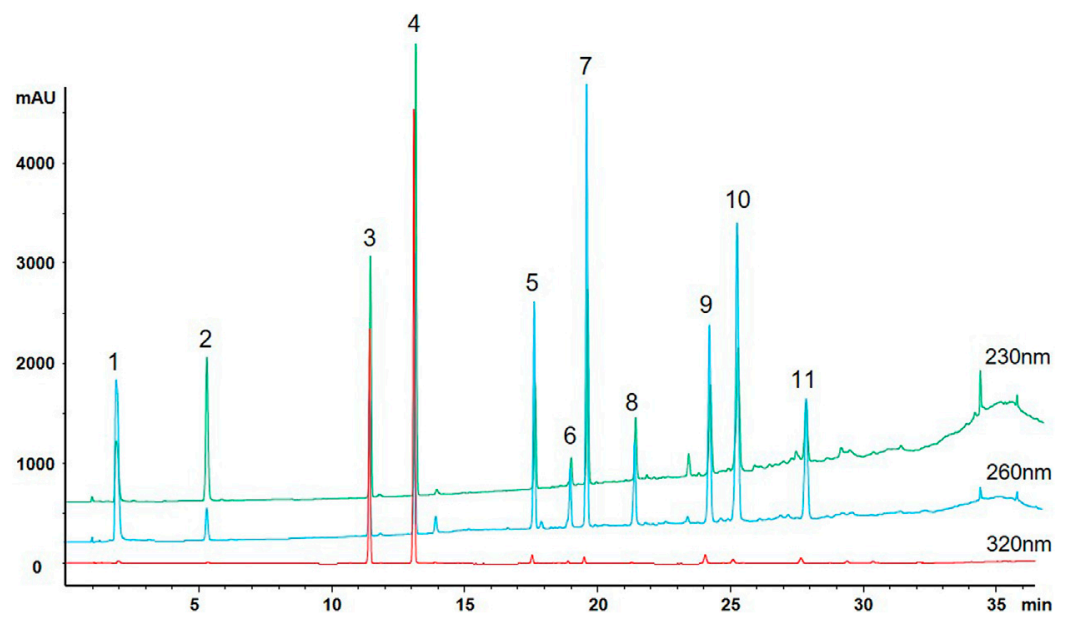

FIGURE 1 | Multiple chromatograms of 11 constituents of PM (1. Gallic acid; 2. Catechin; 3. TSG; 4. Resveratrol; 5. Emodin-Glu; 6. Physcion; 7. Aloe-emodin; 8. Rhein; 9. Emodin; 10. Chrysophanol; 11. Physcion).

TABLE 1 | Content of active ingredients in PM and its different extracts. Data were expressed as mean $\pm \mathrm{SD}$.

\begin{tabular}{lccc} 
Component & PM $(\mathbf{m g} / \mathbf{g})$ & QE-AM $(\mathbf{m g} / \mathbf{g})$ & AE-PM $\mathbf{( m g / g )}$ \\
\hline TSG & $102.62 \pm 5.43$ & $23.83 \pm 2.54$ & $72.80 \pm 4.36^{\star \star \star}$ \\
Emodin & $31.94 \pm 2.66$ & $6.04 \pm 1.23$ & $24.64 \pm 1.52^{* \star \star}$ \\
Physcion & $8.42 \pm 1.33$ & $0.24 \pm 0.01$ & $8.53 \pm 2.44^{\star \star \star}$ \\
Aloe-emodin & $1.44 \pm 0.56$ & $\backslash$ & $0.90 \pm 0.12$ \\
Catechin & $2.36 \pm 0.69$ & $0.26 \pm 0.04$ & $2.85 \pm 0.56^{\star \star \star}$ \\
E-glu & $8.98 \pm 1.01$ & $0.19 \pm 0.02$ & $7.61 \pm 1.05^{\star \star \star}$ \\
P-glu & $1.24 \pm 0.21$ & $0.10 \pm 0.01$ & $1.40 \pm 0.43^{\star \star}$ \\
Gallic acid & $5.16 \pm 1.55$ & $0.32 \pm 0.02$ & $5.42 \pm 1.48^{\star \star \star}$ \\
Resveratrol & $7.15 \pm 2.41$ & $\backslash$ & $7.55 \pm 1.63$ \\
Rhein & $0.85 \pm 0.12$ & $\backslash$ & $0.66 \pm 0.23$ \\
Chrysophanol & $0.66 \pm 0.23$ & $\backslash$ & $0.50 \pm 0.18$ \\
\hline
\end{tabular}

ANOVA test was used to calculate the significance of the differences, ${ }^{* * *} \mathrm{p}<0.001$ and ${ }^{* *} \mathrm{p}<0.01$ which compared with the QE-AM.

emodin, aloe-emodin, physcion, emodin-8-O$\beta$-D-glucoside (E-Glu), physcion-8-O- $\beta$-D-glucoside (P-Glu), gallic acid, catechin, resveratrol, and puerarin ( $\geq 98 \%$ purity) were all procured from the National Institute for the Control of Pharmaceutical and Biological Products (Beijing, China). Sulfatase was obtained from Helix pomatia (Type $H-1$, sulfatase $\geq 10,000$ units/g solid, Sigma, United States). The peptides LTIIPQDPILFSGSLR, GVALPETIEEAENLGR,

AAATEDATPAALEK, TFQFPGDIESSK, LLLSGFQEELR, STALQLIQR, NTTGALTTR, EENLGITK, SVQPELK, and TYPVPFQR, as well as stable isotope-labeled internal standards $(\geq 98 \%$ purity), were synthesized by Bankpeptide Biological Technology, Co., Ltd (Hefei, China). The ProteoExtract native membrane protein extraction kit was purchased from Calbiochem (Temecula, CA, United States). The BCA protein assay kit and in-solution trypsin digestion kit were obtained from Pierce Biotechnology (Rockford, IL, United States). Formic acid was MS grade; ammonium bicarbonate (98\% purity) and sodium deoxycholate $(98 \%$ purity) were purchased from Sinopharm Chemical Reagent, Co., Ltd (Shanghai, China). Acetonitrile and methanol, all MS grade, were obtained from Merk (Darmstadt, Germany). Acetonitrile and methanol, all MS grade, were obtained from Merk (Darmstadt, Germany).

\section{Preparation and Quality Control of Polygonum multiflorum Thunb Extract}

The alcoholic extract of Polygonum multiflorum Thunb (AE-PM) was prepared by immersing $90 \mathrm{~g}$ of PM in $540 \mathrm{ml}$ of $75 \%$ ethanol $(1: 6, \mathrm{w} / \mathrm{v})$ for $0.5 \mathrm{~h}$. The sample was refluxed twice, each time for $1 \mathrm{~h}$. The extraction solution was mixed and passed through a paper filter. Then, the filtrate was concentrated to $30 \mathrm{ml}$, and the final solution containing the crude drug presented a concentration of $3 \mathrm{~g} / \mathrm{ml}$. After that, we carried out a multicomponent assay, as described by Zhao MJ's (Zhao et al., 2017), on the PM, AE-PM, and aqueous extract of PM (QE-PM) for the following constituents: TSG, emodin, physcion, gallic acid, catechin, E-Glu, P-Glu, aloe-emodin, resveratrol. The results are shown in Figure 1 and Table 1. The chemical components of AE$\mathrm{PM}$ were significantly more than that of the QE-PM, so we chose the AE-PM for our pharmacokinetic study.

\section{Animals Handing}

Male Sprague Dawley rats (200-220 g) were purchased from B\&K laboratory Animal, Corp. Ltd (Shanghai, China), fed in the Laboratory Animal Center of Shanghai University of Traditional Chinese Medicine, and housed in an environmentally controlled animal room at a temperature of $22-24^{\circ} \mathrm{C}$ and a relative humidity of $60-65 \%$. The animals were maintained on a 12:12 h light-dark cycle (lights on at 7:00 am) with regulated temperature and humidity. During the entirety of the experimental process, the rats were fed with certified standard rat chow and tap water ad libitum. All efforts were made to reduce animal suffering. The animal experiments strictly complied with 
TABLE 2 | Multiple reaction monitoring parameters of nine chemical components in PM (and internal standard).

\begin{tabular}{|c|c|c|c|c|c|}
\hline Component & Molecular weight & Parent ion & Product ion & Fragmentor & $\begin{array}{c}\text { Collision energy } \\
\text { (V) }\end{array}$ \\
\hline TSG & 406.39 & 404.9 & 243.1 & 156 & 27 \\
\hline Emodin & 270.24 & 268.7 & 224.8 & 170 & 24 \\
\hline Physcion & 284.27 & 283.1 & 240 & 170 & 23 \\
\hline Aloe-emodin & 270.2369 & 268.9 & 239.6 & 150 & 24 \\
\hline Catechin & 290.27 & 289 & 245.1 & 150 & 12 \\
\hline E-glu & 432.11 & 430.9 & 268.8 & 165 & 27 \\
\hline P-glu & 446.404 & 444.9 & 282.7 & 100 & 16 \\
\hline Gallic acid & 170.12 & 168.9 & 125 & 110 & 11 \\
\hline Resveratrol & 228.24 & 227 & 185 & 140 & 15 \\
\hline Puerarin (IS) & 416.378 & 415 & 295 & 165 & 20 \\
\hline
\end{tabular}<smiles>OC[C@H]1O[C@@H](Oc2c(O)cc(O)cc2/C=C/c2ccc(O)cc2)[C@H](O)[C@@H](O)[C@@H]1O</smiles>

2,3,5,4'-tetrahydroxystibene-2-O- $\beta$-glucoside (1)<smiles>[R]c1cc(O)c2c(c1)C(=O)c1cc([R])cc(O[C@@H]3O[C@H](CO)[C@@H](O)[C@H](O)[C@H]3O)c1C2=O</smiles>

Emodin-8-O- $\beta$-glucoside:R1 $=\mathrm{CH} 3, \mathrm{R} 2=\mathrm{OH}(6)$

Physcion-8-O- $\beta$-glucoside:R1=CH3, R2=OCH3 (7)<smiles>[R]c1cc(O)c2c(c1)C(=O)c1cc([R])cc(O)c1C2=O</smiles><smiles>Oc1cc(O)c2c(c1)OC(c1ccc(O)c(O)c1)[C@H](O)C2</smiles>

Emodin: $\mathrm{R} 1=\mathrm{CH} 3, \mathrm{R} 2=\mathrm{OH}(2)$

Physcion: $\mathrm{R} 1=\mathrm{CH} 3, \mathrm{R} 2=\mathrm{OCH} 3(3)$

Aloe-emodin: R1=CH2OH, R2=H (4) Catechin (5)<smiles>Oc1ccc(/C=C/c2cc(O)cc(O)c2)cc1</smiles>

FIGURE 2 | Chemical structures of 9 active components in AE-PM (1. TSG; 2. Emodin; 3. Physcion; 4. Aloe-emodin; 5. Catechin; 6. E-Glu; 7. P-Glu; 8. Gllic acid; 9. Resveratrol).

the Guide for the Care and Use of Laboratory Animals, and the animal experiment protocols were approved by the Institutional Animal Committee of Shanghai University of Traditional Chinese Medicine (Permit No. PZSHUTCM19010406).

\section{PHARMACOKINETIC STUDIES OF AE-PM IN DIFFERENT RAT LIVER DISEASE MODELS}

\section{Instrumentation and Chromatographic Conditions}

To explore the pharmacokinetic properties of PM following intragastric administration in rats, a rapid and sensitive method involving the use of UHPLC-MS/MS (Agilent 6460 series, Agilent Technologies, Santa Clara, CA, United States) was developed and validated for the simultaneous quantification of nine active components in rat plasma. The quantification was conducted in ESI negative ionization mode, and mass spectrometry conditions were set up as follows: capillary voltage of $3500 \mathrm{~V}$; gas flow at $12 \mathrm{~L} / \mathrm{min}$; nebulizer of $40 \mathrm{psi}$; the gas temperature of $350^{\circ} \mathrm{C}$; and delta EMV (-) of 400 . A $10 \mu \mathrm{l}$ extraction sample was injected into the column (Agilent SBC18 column, $2.1 \mathrm{~mm} \times 50 \mathrm{~mm}, 1.8 \mathrm{~mm}$ ) and eluted at $0.4 \mathrm{ml} / \mathrm{min}$ with a gradient elution of water (with $0.1 \% \mathrm{v} / \mathrm{v}$ formic acid) (A) and acetonitrile (B) (0-1.5 min, 20-30\% B; 1.5-3.5 min, 30-50\% B; 3.five to four $\min , 50-55 \% \mathrm{~B}$; $4-6.5 \mathrm{~min}, 55-85 \% \mathrm{~B}$; $6.5-6.6$ $\mathrm{min}, 85-20 \% \mathrm{~B}$ and re-equilibration for $3 \mathrm{~min}$ ). Multiple reaction monitoring parameters and chemical structures of nine chemical 
components in PM (and internal standard) are shown in Table 2 and Figure 2.

\section{Sample Preparation}

A selective sample preparation method was applied to eliminate endogenous proteins' interference and optimize extraction recovery. Among several chemical reagent methanol and acetonitrile, and acetonitrile combined with methanol and formic acid, were used. Moreover, the amounts of extraction solvent were all tested before. The application of triple methanol resulted in the highest sensitivity level and convenience, especially minimizing endogenous interference and enhancing extraction recovery. Therefore, we selected it as the optimal solvent for sample preparation.

The sulfatase chosen for this experiment contains $\beta$-glucuronidase activity, which could hydrolyze both glucuronide and sulfate conjugation metablites of components in PM into a prototype drug. According to the product information, the optimal working temperature of the sulfatase is $37^{\circ} \mathrm{C}$, and the $\mathrm{pH}$ value if 5 . According our previous results (Ding et al., 2012; Yi et al., 2018), the maximum hydrolysis of phase II metabolites was achieved when the sulfatase (330 units/ $\mathrm{ml}$ ) was incubated for $30 \mathrm{~min}$ at a volume ratio of 1:1 with the plasma sample.

A $50 \mu \mathrm{l}$ aliquot of blood plasma sample was placed in a centrifuge tube with $50 \mu \mathrm{l}$ of puerarin (internal standard, IS) solution $(1,000 \mathrm{ng} / \mathrm{ml})$, followed by $150 \mu \mathrm{l}$ methanol, which was mixed for $5 \mathrm{~min}$. Then, the mixture was centrifuged for $10 \mathrm{~min}$ at $15,000 \mathrm{rpm}\left(4^{\circ} \mathrm{C}\right)$, the supernatant was transferred to a clean centrifuge tube and dried with nitrogen gas at room temperature. The residue was resuspended in $100 \mu$ l of methanol, then centrifuged at $15,000 \mathrm{rpm}\left(4^{\circ} \mathrm{C}, 10 \mathrm{~min}\right)$, and $10 \mu \mathrm{l}$ of the supernatant was analyzed by UHPLC-MS/MS.

Additional plasma samples $(50 \mu \mathrm{l})$ were enzymatically hydrolyzed with $50 \mu \mathrm{l}$ of enzyme solution $(65.86 \mathrm{mg}$ of sulfatase, dissolved in $2 \mathrm{ml}$ of sodium acetate buffer, $\mathrm{pH} 5.0$ ) for phase II metabolite quantification, in accordance with our previous study (Ding et al., 2012; Yi et al., 2018). After being vortex mixed for $5 \mathrm{~min}$, the mixture was incubated at $37^{\circ} \mathrm{C}$ for $30 \mathrm{~min}$ and returned to room temperature. Subsequently, the samples were processed as described above.

\section{METHOD VALIDATION}

The UPLC-MS/MS method for determining the nine ingredients in rat blood plasma was validated according to the current US FDA Bioanalytical Method Validation Guidance (Guidance for Industry: Bioanalytical Method Validation, 2001) (Yuan et al., 2020). The following parameters were determined: specificity, linearity, lower limit of quantitation (LLOQ), accuracy, precision, extraction recovery, matrix effect, and stability.

\section{Specificity}

The purpose of specificity analysis is to eliminate the interference of endogenous substances on the determination. Specificity was determined by comparing chromatograms of blank rat blood plasma obtained from six individual subjects with chromatograms of blood plasma samples obtained after AEPM administration at a dose of $50 \mathrm{~g} / \mathrm{kg}$.

\section{Linearity}

Calibration curves were constructed using the peak area ratios of the analytes to puerarin and by applying a weighted $\left(1 / \mathrm{x}^{2}\right)$ least squares linear regression analysis. The LLOQ was determined at the lowest concentrations at the signal-to-noize ratio $(\mathrm{S} / \mathrm{N}) \geq 10$.

\section{Accuracy and Precision}

Precision [expressed as the relative standard deviation (RSD)] and accuracy [expressed as the relative error (RE)] were calculated for three QC points (low, medium, and high). Six replicates of each QC point were analyzed to determine the interday accuracy and precision. This process was repeated three times over three consecutive days to determine the intraday accuracy and precision.

\section{Extraction Recovery and Matrix Effect}

Recovery was evaluated in six replicates at three different QC concentrations (low, medium, and high). The percentage recovery was determined by comparing the concentrations of the pre-extraction spiked QC samples prepared in a blank matrix (by adding analytes and puerarin to blank matrix prior to extraction) with the peak area of the post-extraction spiked QC samples prepared in an extracted blank matrix (prepared by adding analytes and puerarin to blank matrix extract). Matrix effects were investigated on six independent sources of blank rat blood plasma by calculating the ratio of the peak area in the presence of matrix to the peak area in the absence of matrix at three different QC concentrations (low, medium, and high).

\section{Stability}

The stability of standard analytes in rat plasma was evaluated under several conditions (time and temperature) by analyzing six replicates of the QC samples at three concentrations (low,medium, and high). Stability was investigated in terms of short and long-term stability, freeze and thaw stability, and postpreparative stability by using the developed method. Short-term stability was evaluated by storing QC samples at room temperature $\left(25^{\circ} \mathrm{C}\right)$ for $24 \mathrm{~h}$. Long-term stability was assessed after 60 days by a storage at $-80^{\circ} \mathrm{C}$. Freeze and thaw stability were determined after three freeze-thaw cycles at $-80^{\circ} \mathrm{C}$. In addition, post-preparative stability during storage in an auto sampler at $4^{\circ} \mathrm{C}$ for $24 \mathrm{~h}$ was investigated.

\section{Application to Pharmacokinetic Analysis}

The rats were randomly distributed into three groups $(n=12$ for each group: 1) normal group (group 1; 2) ANIT group (group 2; and 3) $\mathrm{CCl}_{4}$ group (group 3). Group 1 served as non-treated controls, whereas group 2 was treated with $4 \%$ ANIT at a dose of $50 \mathrm{mg} / \mathrm{kg}$ (diluted in olive oil) to induce cholestatic liver injury. Additionally, group 3 represented the $\mathrm{CCl}_{4}$-induced hepatocytes injury model, which was treated with pure $\mathrm{CCl}_{4}(5 \mathrm{ml} / \mathrm{kg}$, s. c.) on day $0,50 \% \mathrm{CCl}_{4}$ (diluted in olive oil) $(3 \mathrm{ml} / \mathrm{kg}$, s. c.) on day 3 , and $20 \% \mathrm{CCl}_{4}$ (diluted in olive oil) $(3 \mathrm{ml} / \mathrm{kg}$, s. c.) on day 6 . After $24 \mathrm{~h}$, 
TABLE 3 | Multiple reaction monitoring parameters of peptides (and internal standard) selected for targeted analysis of hepatobiliary transporters.

\begin{tabular}{|c|c|c|c|c|c|c|}
\hline Transports & Signature pedtides & Molecular weight & $\begin{array}{l}\text { Parent ion } \\
\quad(z=2)\end{array}$ & $\begin{array}{l}\text { Product ion } \\
\qquad(z=1)\end{array}$ & Fragmentor & Collision energy \\
\hline Mrp2 & LTIIPQDPILFSGSLR & 1770.08 & 885.7 & 1,329.9 & 200 & 25 \\
\hline Oct1 & GVALPETIEEAENLGR & $1,697.84$ & 849.7 & $1,357.8$ & 180 & 29 \\
\hline Ntcp & AAATEDATPAALEK & $1,358.42$ & 680 & 915.5 & 140 & 18 \\
\hline IS & AAATEDATPAALEK* & $1,366.42$ & 684 & 923 & 140 & 23 \\
\hline Oatp1a4 & TFQFPGDIESSK & $1,355.45$ & 678.6 & 832.3 & 160 & 19 \\
\hline Mate1 & LLLSGFQEELR & $1,304.48$ & 652.9 & 965 & 140 & 24 \\
\hline Bsep & STALQLIQR & $1,029.19$ & 515.5 & 529.5 & 130 & 17 \\
\hline Mdr1 & NTTGALTTR & 934.00 & 467.9 & 719.4 & 110 & 14 \\
\hline Oatp1a1 & EENLGITK & 903.00 & 452.3 & 468.1 & 120 & 8 \\
\hline Oatp1a2 & SVQPELK & 799.91 & 400.8 & 486.3 & 110 & 9 \\
\hline UGT1A1 & TYPVPFQR & $1,336.48$ & 504.5 & 547.1 & 140 & 19 \\
\hline
\end{tabular}

five rats selection for serum and liver collection from each of the three groups. Blood samples were collected in a coagulation tube, and were centrifuged at $4^{\circ} \mathrm{C}$ for $15 \mathrm{~min}(4,000 \mathrm{rpm})$, The resultant serum was used for the ALT, AST, TBIL, DBIL, TBA and ALP assays. Liver samples were dissected and stored at $-80^{\circ} \mathrm{C}$ for further analysis, whereas the central part of the right large lobe of the liver was used for histological examination.

The remaining 21 rats of the three groups were treated with a single oral dose of AE-PM (50.4 g PM/kg). This dosage was chosen based on previous studies to liver injury in normal rats after long-term administration. Blood was collected in heparinized tubes at 5, 15, 30, 45, 60, 120, 240, 360, 480, 720, $1,440,2,880$, and 4,320 min after administration. The blood samples were centrifuged at $5,000 \mathrm{rpm}\left(4^{\circ} \mathrm{C}\right)$ for $7 \mathrm{~min}$, and the supernatant plasma was harvested.

\section{DETERMINATION OF UGT1A1 AND NINE OTHER TRANSPORTER PROTEINS IN THE LIVER}

The detection method for UGT1A1 and nine other transporter proteins in the liver was comprehensively investigated in our study (35). We analyzed the different expression levels of bilirubin metabolizing enzyme and transporters in the liver of rats from the healthy animals, $\mathrm{ANIT}$, and $\mathrm{CCl}_{4}$ model groups.

\section{Instrumentation and Chromatographic Conditions}

An Agilent 1290 Infinity series UHPLC system coupled to an Agilent 6460 series MS/MS system (Agilent Technologies, Santa Clara, CA, United States) was applied to quantitate the signature peptides in ESI positive ionization mode. The mass spectrometry conditions were set up as follows: capillary voltage of $2000 \mathrm{~V}$; gas flow at $8 \mathrm{~L} / \mathrm{min}$; nebulizer at $30 \mathrm{psi}$; gas temperature, $300^{\circ} \mathrm{C}$; delta EMV (+) of 400 . A $5 \mu$ l digest sample was injected into the column (Agilent SB-C18 column, $2.1 \mathrm{~mm} \times 50 \mathrm{~mm}, 1.8 \mathrm{~mm}$ ) and eluted at $0.4 \mathrm{ml} / \mathrm{min}$ with a gradient elution of water (with $0.05 \%$ $\mathrm{v} / \mathrm{v}$ formic acid) (A) and acetonitrile (B) (0-1 min, $5-5 \% \mathrm{~B}$; 1-4 min, 5-60\% B; 4-5 min, 60-5\% B; and re-equilibration for $3 \mathrm{~min}$ ). The sequence of characteristic peptides that corresponded to UGT1A1 and the other nine transporter proteins were based on our previous experiments and listed in Table 3.

\section{Sample Preparation}

Total membrane protein was isolated (in triplicate) from liver tissue samples according to the Native Membrane Protein Extraction Kit protocol. Subsequently, protein concentrations were determined by the BCA Protein Assay Kit. $10 \mu \mathrm{l}$ of $5 \mathrm{mg} / \mathrm{ml}$ (or lower concentration) of a hepatocyte membrane protein incubated with $20 \mu \mathrm{l}$ of dithiothreitol $(100 \mathrm{mM})$ and $50 \mu \mathrm{l}$ of ammonium bicarbonate buffer ( $50 \mathrm{mM}, \mathrm{pH} \mathrm{7.8)}$. After incubation at $95^{\circ} \mathrm{C}$ for $5 \mathrm{~min}, 20 \mu \mathrm{l}$ of iodoacetamide $(20 \mathrm{mM})$ was added to the mixture, followed by incubation at $37^{\circ} \mathrm{C}$ for $20 \mathrm{~min}$ in the dark. To concentrate the samples, ice-cold methanol $(0.5 \mathrm{ml})$, chloroform $(0.2 \mathrm{ml})$, and water $(0.2 \mathrm{ml})$ were added. After centrifugation at $4^{\circ} \mathrm{C}$ for $5 \mathrm{~min}$ at $16,000 \mathrm{~g}$, the supernatant was discarded and the pellet was washed once with ice-cold methanol $(0.25 \mathrm{ml})$ and resuspended with $40 \mu \mathrm{l}$ of reconstitution solution (equal volume of $3 \%$ sodium deoxycholate $(\mathrm{w} / \mathrm{v})$ and $5 \mathrm{mM}$ ammonium bicarbonate buffer). Finally, the protein sample was digested with $10 \mu \mathrm{l}$ of trypsin. The protein-to-trypsin ratio was 25:1 (w/w). After incubation at $37^{\circ} \mathrm{C}$ for $24 \mathrm{~h}$, the digestion reaction was quenched by $60 \mu \mathrm{l}$ of IS cocktail (prepared in 15\% acetonitrile in water). The samples were centrifuged at $5,000 \mathrm{~g}$ for $5 \mathrm{~min}$ at $4^{\circ} \mathrm{C}$, and $5 \mu \mathrm{l}$ of the supernatant was injected in the UHPLC-MS/MS system.

\section{Data Processing and Statistical Analysis}

All data were presented as mean \pm standard deviation (SD). A one-way analysis of variance (ANOVA) was used to compare the data between three groups. The differences were considered to be statistically significant when $p<0.05$ and highly significant when the $p$-value was $<0.01$ or $p<0.001$. Spearman rank correlation coefficient, calculated by bivariate correlation analysis was used to evaluate the correlation between AUC values and expression levels of metabolic enzyme and transporters. All statistical analyses were performed with the SPSS Statistics system (SPSS vision 21.0). Pharmacokinetic data analyses were performed using DAS 2.1.1 software (Mathematical Pharmacology Professional Committee of China, Shanghai, China). 

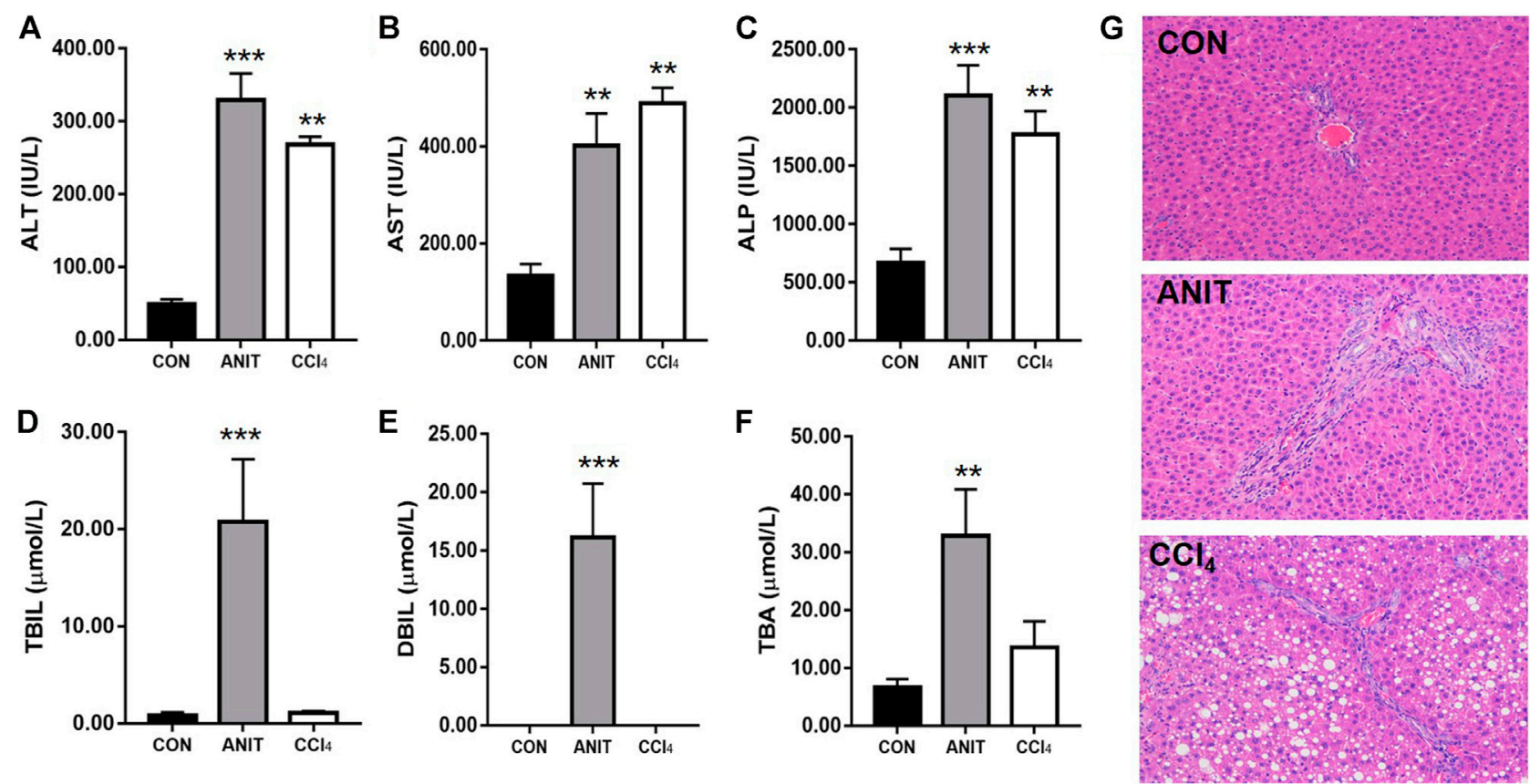

FIGURE 3 | The results of serum biochemical and histopathological examination. (A-F) The serum ALT, AST, ALP, TBIL, DBIL, TBA, respectively. (G) Typical histopathological section photographs of rat liver speciments for H\&E analysis ( $\times 40$ magnification) $\left(^{* \star} p<0.01\right.$ and ${ }^{\star \star \star} p<0.001$ which compared with the control group).

\section{RESULTS}

\section{Serum Biochemistry and Histopathological Examination}

The serum biochemical parameters such as TBIL, DBIL, ALT, and AST, were significantly increased in ANIT and $\mathrm{CCl}_{4}$ groups, and the livers also showed different pathological changes compared to the control group. In order to confirm the feasibility of our two pathological models, we examined the serum biochemical parameters and liver sections. The biochemistry serum results of ALT, AST, ALP, TBIL, DBIL, and TBA were presented in Figures 3A-F. ALT and AST are well-recognized markers of hepatocyte damage. As shown in Figures 3A,B the rats in group $\mathrm{CCl}_{4}$ dose efficiently increased the serum levels of ALT and AST to 4.45 and 2.68-folds ( $p<$ 0.001 ) respectively, compared with the control group, indicating that severe hepatocyte damage occurred after $\mathrm{CCl}_{4}$ administration. TBIL, DBIL, TBA and ALP were significantly increased in rats with cholestatic liver injury. As shown in Figures 3C-F, the rats in group ANIT dose efficiently increased the serum levels of TBIL, DBIL, TBA and ALP to 23.73, 1,612.00, 3.93 and 2.16 -folds $(p<0.001)$ respectively, suggesting a severe cholestatic liver injury occurred after continuous administration of ANIT compared with the control group.

Liver sections from the healthy control group and the pathological model groups stained with hematoxylin and eosin were examined by microscopy to provide visual evidence. As shown in Figure 3G, the liver sections of the control animals showed normal hepatocyte structures. Marked cholestasis in terms of acute neutrophil infiltration, sinusoid congestion, and necrosis of the interlobular ducts and hepatocytes could be distinguished in specimens of ANIT-treated rats, compared with the livers from the healthy controls. The tissues from the $\mathrm{CCl}_{4}$ group showed disturbed hepatocyte arrangement, large number of hepatocytes with fatty degeneration in the form of vacuoles, few inflammatory infiltration and necrosis compared with the healthy control group. Two models of pathological liver injury were successfully established considering the results of serum biochemical and histopathological examination.

\section{PHARMACOKINETIC STUDIES OF AE-PM IN DIFFERENT RAT MODELS}

\section{Method Validation}

\section{Specificity}

The method selectivity was evaluated by comparing chromatograms of six extracted blank plasma samples of different sources with those of spiked plasma samples containing nine compounds and puerarin. Figures $\mathbf{4 A}, \mathbf{B}$ shows the total ion chromatograms of the blank plasma sample and the QC samples spiked with nine components and puerarin by MRM scan, respectively. In addition, the real subject's plasma sample total ion chromatograms collected at 60 min after the administration of AE-AM by oral gavage was presented in Figure 4C. Under optimal method conditions, no endogenous peaks of the analytes were observed in the retention time in any of the blank rat plasma batches, indicating that there 


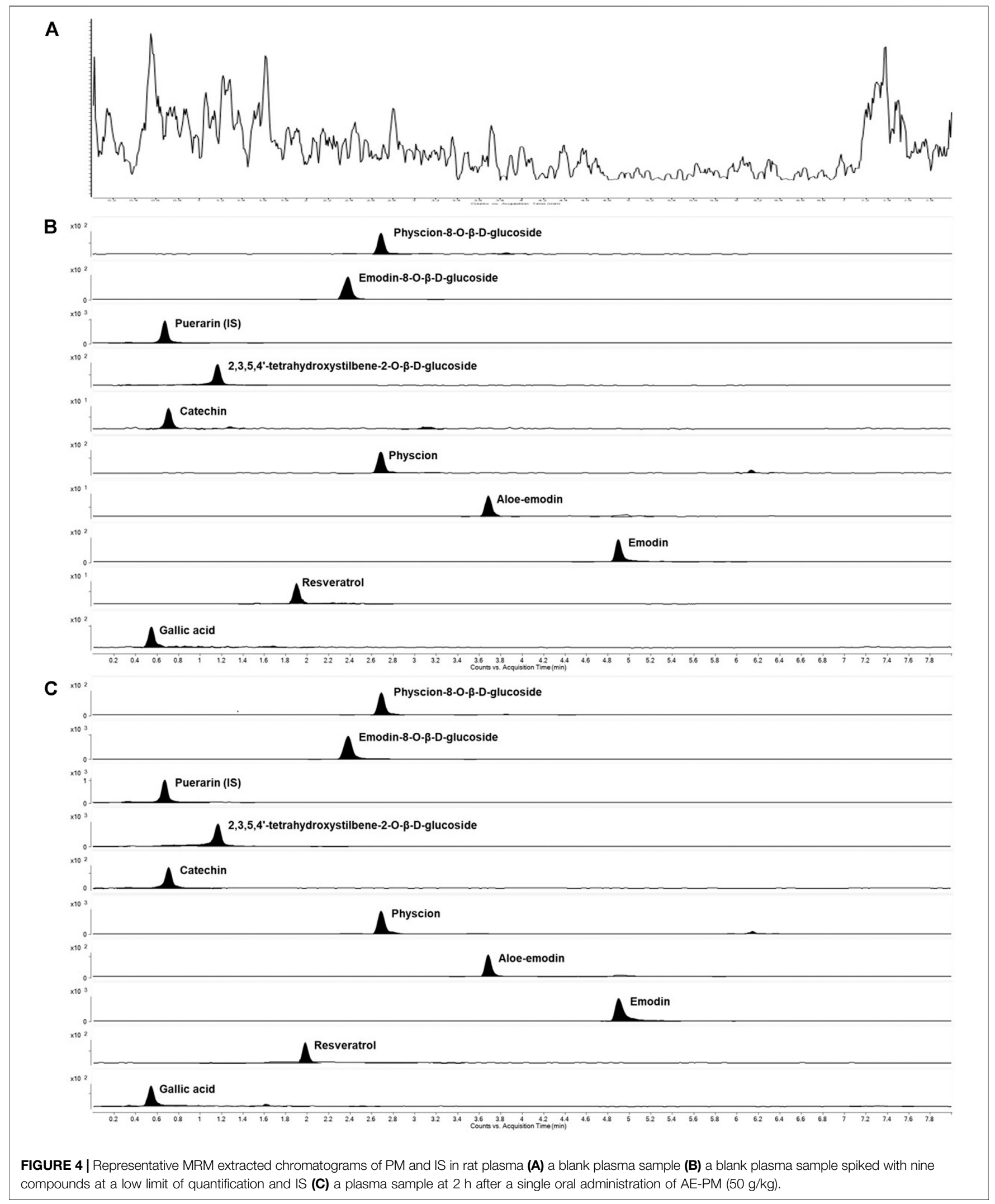


TABLE 4 | The results of linearity.

\begin{tabular}{|c|c|c|c|c|}
\hline Component & Regression equation & $R^{2}$ & Linearity range (ng/ml) & LLOQ (ng/ml) \\
\hline TSG & $Y=0.006107^{\star} X+0.029365$ & 0.9923 & $7.64-29,650.00$ & 7.64 \\
\hline Emodin & $Y=0.026532^{\star} X+0.118,645$ & 0.9987 & $7.67-38,375.00$ & 7.67 \\
\hline Physcion & $Y=0.001945^{\star} X+0.064853$ & 0.9901 & $6.06-13,100.00$ & 6.06 \\
\hline Aloe-emodin & $Y=0.016824^{\star} X+0.032567$ & 0.9972 & $5.92-5,800.00$ & 5.92 \\
\hline Catechin & $Y=0.012869^{\star} X+0.06594$ & 0.9900 & $9.28-9,500.00$ & 9.28 \\
\hline E-glu & $Y=0.017420^{*} X-0.055301$ & 0.9933 & $6.01-12,700.00$ & 6.01 \\
\hline P-glu & $Y=0.008064^{*} X+0.024517$ & 0.9910 & $6.42-2,468.00$ & 6.42 \\
\hline Gallic acid & $Y=9.301,334^{*} X+0.007394$ & 0.9811 & $6.66-2,560.00$ & 6.66 \\
\hline Resveratrol & $Y=0.000643^{\star} X+0.003861$ & 0.9916 & $8.39-17,200.00$ & 8.39 \\
\hline
\end{tabular}

\begin{tabular}{|c|c|c|c|c|c|c|c|c|}
\hline \multirow[t]{2}{*}{ Component } & \multirow[t]{2}{*}{ Concentration (ng/ml) } & \multicolumn{2}{|c|}{ Intra-day precision } & \multicolumn{2}{|c|}{ Inter-day precision } & \multicolumn{3}{|c|}{ Accuracy } \\
\hline & & Mean (ng/ml) & RSD (\%) & Mean (ng/ml) & RSD (\%) & Mean (ng/ml) & RE (\%) & RSD (\%) \\
\hline \multirow[t]{3}{*}{ TSG } & $14,825.00$ & $14,876.26$ & 4.1 & $15,023.17$ & 4.2 & $15,981.35$ & 7.8 & 2.3 \\
\hline & 741.25 & 740.84 & 6.6 & 747.81 & 6.9 & 730.87 & -1.4 & 4.1 \\
\hline & 14.83 & 13.69 & 6.2 & 12.23 & 3.1 & 17.23 & 16.2 & 3.2 \\
\hline \multirow[t]{3}{*}{ Emodin } & $38,375.00$ & $38,406.12$ & 6.9 & $37,697.78$ & 6.3 & $19,590.44$ & 2.1 & 5.9 \\
\hline & 767.50 & 773.6 & 3.5 & 783.09 & 1.1 & 745.24 & -2.9 & 7.7 \\
\hline & 15.28 & 14.02 & 6.8 & 13.94 & 7.9 & 16.96 & 11.0 & 7.3 \\
\hline \multirow[t]{3}{*}{ Aloe-emodin } & $2,900.00$ & $3,012.06$ & 9.3 & $2,987.48$ & 3.6 & $2,876.80$ & -0.8 & 12.9 \\
\hline & 362.50 & 356.72 & 4.1 & 325.67 & 2.2 & 362.14 & -0.1 & 2.7 \\
\hline & 12.79 & 11.64 & 6.3 & 10.44 & 11.1 & 12.78 & -0.1 & 2.0 \\
\hline \multirow[t]{3}{*}{ Physcion } & $6,550.00$ & $6,618.43$ & 3.3 & $6,667.23$ & 2.9 & $7,015.05$ & 7.1 & 4.2 \\
\hline & 409.38 & 419.55 & 10.9 & 431.57 & 10.4 & 468.33 & 14.4 & 6.2 \\
\hline & 12.79 & 13.65 & 13.2 & 10.49 & 14.3 & 13.35 & 4.4 & 1.5 \\
\hline \multirow[t]{3}{*}{ E-glu } & $6,350.00$ & $6,354.33$ & 2.0 & $6,025.67$ & 1.3 & $6,464.30$ & 1.8 & 4.6 \\
\hline & 396.88 & 396.16 & 4.2 & 405.48 & 4.3 & 359.97 & -9.3 & 3.7 \\
\hline & 12.40 & 11.22 & 5.5 & 12.19 & 6.1 & 13.22 & 6.6 & 2.8 \\
\hline \multirow[t]{3}{*}{ P-glu } & $1,233.30$ & $1,227.31$ & 2.1 & 1,373.63 & 2.0 & $1,139.57$ & -7.6 & 3.3 \\
\hline & 205.50 & 208.37 & 5.1 & 208.73 & 7.4 & 212.28 & 3.3 & 5.2 \\
\hline & 12.84 & 12.42 & 3.9 & 12.92 & 2.9 & 13.69 & 6.6 & 13.9 \\
\hline \multirow[t]{3}{*}{ Gallic acid } & $1,280.00$ & $1,272.00$ & 3.2 & $1,351.00$ & 8.1 & $1,154.56$ & -9.8 & 10.2 \\
\hline & 213.32 & 217.25 & 6.1 & 228.94 & 5.3 & 220.79 & 3.5 & 6.3 \\
\hline & 13.32 & 15.64 & 5.1 & 12.82 & 6.8 & 14.47 & 8.6 & 2.6 \\
\hline \multirow[t]{3}{*}{ Catechin } & $4,750.00$ & $4,707.67$ & 6.4 & $4,450.67$ & 4.7 & $4,617.00$ & -2.8 & 5.3 \\
\hline & 296.87 & 287.48 & 8.6 & 278.82 & 3.4 & 299.24 & 0.8 & 11.6 \\
\hline & 18.56 & 18.06 & 3.4 & 17.9 & 8.9 & 20.94 & 12.8 & 8.4 \\
\hline \multirow[t]{3}{*}{ Resveratrol } & $8,600.00$ & $8,584.83$ & 2.9 & $8,545.67$ & 2.3 & $9,571.80$ & 10.9 & 6.0 \\
\hline & 537.50 & 550.09 & 2.6 & 569.86 & 1.7 & 539.65 & -3.0 & 6.5 \\
\hline & 16.78 & 17.50 & 5.8 & 17.00 & 6.7 & 15.49 & -3.6 & 5.7 \\
\hline
\end{tabular}

was no significant endogenous interference of the MRM mode with the analytes during the assay.

\section{Linearity}

The calibration curves of the nine compounds were constructed respectively by plotting the peak-area ratio of each analyte to puerarin (y) vs each analyte concentration $(\mathrm{ng} / \mathrm{ml})(\mathrm{x})$ in spiked blank rat plasma. The method was linear over the concentration range of $7.64-29,650.00 \mathrm{ng} / \mathrm{ml}$ for TSG, $7.67-38,375.00 \mathrm{ng} / \mathrm{ml}$ for emodin, $5.92-5,800.00 \mathrm{ng} / \mathrm{ml}$ for aloe-emodin, $6.06-13,100.00 \mathrm{ng} / \mathrm{ml}$ for physcion, $6.01-12,700.00 \mathrm{ng} / \mathrm{ml}$ for E-Glu, $6.42-2,468.00 \mathrm{ng} / \mathrm{ml}$ for P-Glu, $6.66-2,560.00 \mathrm{ng} / \mathrm{ml}$ for gallic acid, $9.28-9,500.00 \mathrm{ng} / \mathrm{ml}$ for catechin, and $8.39-17,200.00 \mathrm{ng} / \mathrm{ml}$ for resveratrol. A signal noise ratio $(\mathrm{S} / \mathrm{N})$ $\geq 10$ at the LLOQ was observed for all the analytes. In addition, it was observed that the LLOQ was7.64 $\mathrm{ng} / \mathrm{ml}$ for TSG, $7.67 \mathrm{ng} / \mathrm{ml}$ for emodin, $5.92 \mathrm{ng} / \mathrm{ml}$ for aloe-emodin, $6.06 \mathrm{ng} / \mathrm{ml}$ for physcion, $6.01 \mathrm{ng} / \mathrm{ml}$ for E-Glu, $6.42 \mathrm{ng} / \mathrm{ml}$ for P-Glu, $6.66 \mathrm{ng} / \mathrm{ml}$ for gallic acid, $9.28 \mathrm{ng} / \mathrm{ml}$ for catechin, and $8.39 \mathrm{ng} / \mathrm{ml}$ for resveratrol. And the square of correlation coefficients $\left(\mathrm{R}^{2}\right)$ was greater than 0.9811 . The linear regression equations and correlation coefficients $\left(R^{2}\right)$ of the analytes are listed in Table 4.

\section{Accuracy and Precision}

The accuracy and inter-day and intra-day precisions data at three concentrations of the nine analytes are listed in Table 5. Accuracy was calculated as RE\% $=($ measured samples/spiked plasma- 1$) \times$ $100 \%$; the derived relative errors ranged from $-9.8-16.2 \%$. The 
TABLE 6 | The results of matrix effect and recovery.

\begin{tabular}{|c|c|c|c|c|c|}
\hline \multirow[t]{2}{*}{ Component } & \multirow[t]{2}{*}{ Concentration (ng/ml) } & \multicolumn{2}{|c|}{ Extraction recovery (\%) } & \multicolumn{2}{|c|}{ Matrix effect (\%) } \\
\hline & & Mean (\%) & RSD (\%) & Mean (\%) & RSD (\%) \\
\hline \multirow[t]{3}{*}{ TSG } & $14,825.00$ & 96.1 & 4.3 & 102.7 & 5.2 \\
\hline & 741.25 & 81.7 & 5.2 & 96.6 & 3.8 \\
\hline & 14.83 & 72.7 & 4.3 & 68.3 & 4.2 \\
\hline \multirow[t]{3}{*}{ Emodin } & $38,375.00$ & 102.7 & 4.0 & 102.7 & 5.9 \\
\hline & 767.50 & 104.6 & 4.6 & 105.7 & 9.3 \\
\hline & 15.28 & 99.3 & 2.6 & 99.7 & 1.1 \\
\hline \multirow[t]{3}{*}{ Aloe-emodin } & $2,900.00$ & 102.3 & 2.4 & 100.9 & 2.5 \\
\hline & 362.50 & 82.4 & 3.3 & 103.2 & 9.3 \\
\hline & 12.79 & 92.5 & 2.4 & 83.9 & 5.2 \\
\hline \multirow[t]{3}{*}{ Physcion } & $6,550.00$ & 102.1 & 3.3 & 98.5 & 1.4 \\
\hline & 409.38 & 90.9 & 3.8 & 101.7 & 2.4 \\
\hline & 12.79 & 80.0 & 7.2 & 91.0 & 4.1 \\
\hline \multirow[t]{3}{*}{ E-glu } & $6,350.00$ & 102.9 & 4.1 & 100.4 & 3.0 \\
\hline & 396.88 & 99.8 & 3.1 & 101.2 & 5.6 \\
\hline & 12.40 & 91.6 & 2.3 & 91.6 & 4.7 \\
\hline \multirow[t]{3}{*}{ P-glu } & $1,233.30$ & 94.8 & 3.1 & 99.6 & 4.8 \\
\hline & 205.50 & 83.9 & 6.7 & 94.3 & 4.0 \\
\hline & 12.84 & 79.5 & 7.6 & 82.4 & 5.4 \\
\hline \multirow[t]{3}{*}{ Gallic acid } & $1,280.00$ & 75.6 & 5.0 & 95.2 & 4.0 \\
\hline & 213.32 & 65.2 & 4.3 & 76.2 & 5.2 \\
\hline & 13.32 & 48.9 & 14.5 & 58.5 & 12.0 \\
\hline \multirow[t]{3}{*}{ Catechin } & $4,750.00$ & 50.5 & 6.3 & 99.0 & 2.5 \\
\hline & 296.87 & 52 & 8.4 & 102.4 & 6.8 \\
\hline & 18.56 & 50.7 & 14.3 & 77 & 8.1 \\
\hline \multirow[t]{3}{*}{ Resveratrol } & $8,600.00$ & 93.9 & 4.3 & 99.1 & 1.4 \\
\hline & 537.50 & 74.4 & 3.8 & 98 & 1.2 \\
\hline & 16.78 & 72.1 & 3.7 & 72.9 & 8.0 \\
\hline
\end{tabular}

inter-day and intra-day precision were in the ranges of $1.1-14.3$ and $2.0-13.2 \%$ at all QC levels, respectively. The results showed that the method has good accuracy and precision, and was suitable for the pharmacokinetic analysis of all components.

\section{Extraction Recovery and Matrix Effect}

The results of the matrix effect and extraction recovery of all components at three concentrations are shown in Table 6. The recovery range was from 48.9 to $104.6 \%$ at low, medium, and high concentrations for the nine constituents (RSD $<14.5 \%$ ), and the absolute matrix effect values ranged from 58.5 to $105.7 \%$, with the RSD value being lower than $12.0 \%$. The results indicated no coeluting peaks, which may have influenced the ionization of all components and puerarin.

\section{Stability}

The stability of QC samples of the nine compounds were tested under three different conditions (Table 7). All compounds were shown to be stable (RSD ranged from 1.7 to $12.6 \%$ ) in rat plasma at room temperature for $24 \mathrm{~h}$. After extraction, all analytes were found to be stable (RSD range from 1.3 to $13.8 \%$ ) in the reconstitution solution at $4^{\circ} \mathrm{C}$ for $24 \mathrm{~h}$. Besides, all compounds were shown to be stable (RSD ranged from 1.7 to $14.9 \%$ ) for three freeze-thaw cycles in rat plasma. In our experiment, it was also observed that the unprocessed QC samples were stable (RSD range from 1.5 to $13.9 \%$ ) for 60 days when stored at $-80^{\circ} \mathrm{C}$. The data indicated that the nine compounds in plasma were all stable for $24 \mathrm{~h}$ at room temperature, three freeze/thaw cycles, $24 \mathrm{~h}$ at $4^{\circ} \mathrm{C}$, and for 60 days when stored at $-80^{\circ} \mathrm{C}$.

\section{Pharmacokinetics Study on the Major Components and Phase II Metabolites}

Following the administration of AW-PM, eight prototype components (TSG, emodin, physcion, E-Glu, P-Glu, aloeemodin, catechin, and gallic acid) and five phase II metabolites (TSG, emodin, catechin, and physcion) could be detected by UPLC-MS/MS method. Resveratrol has been fully converted into a phase II metabolite and could not be detected directly. The mean plasma concentration-time profiles of TSG, emodin, physcion, aloe-emodin, callic acid, catechin, E-Glu, and P-Glu in normal, cholestatic and hepatocytes damaged rats are shown in Figure 5A. TSG, emodin and catechin had been partially converted into phase II metabolites, as shown in Figure 5B. The pharmacokinetic behaviors of the majority of PM components were significantly different in the ANIT and $\mathrm{CCl}_{4}$ model rats when compared with the control group. The pharmacokinetic data are shown in Table 8.

Compared with the normal group, the AUC $(0-\infty)$ and Cmax values of TSG in the ANIT model increased by $2,548.17 \%$ and $560.12 \%$, respectively, and 802.14 and $236.59 \%$ respectively in the $\mathrm{CCl}_{4}$ model. The AUC (0- $\left.-\infty\right)$ values of emodin, physcion and E-Glu increased by $75.69,29.24$, and $655.90 \%$ respectively in $\mathrm{CCl}_{4}$ model group, and the Cmax values increased by 57.02, 173.72, and $620.15 \%$ respectively. While in the ANIT model, the AUC (0- 
TABLE 7 | The results of stability.

\begin{tabular}{|c|c|c|c|c|c|c|c|c|c|}
\hline Component & $\begin{array}{c}\text { Concentration } \\
\text { (ng/ml) }\end{array}$ & $\begin{array}{c}\text { Room } \\
\text { temperature } \\
24 \mathrm{~h}(\mathrm{ng} / \mathrm{mL})\end{array}$ & RSD (\%) & $\begin{array}{l}4^{\circ} \mathrm{C} 24 \mathrm{~h} \\
\text { (ng/ml) }\end{array}$ & RSD (\%) & $\begin{array}{l}\text { Freeze- } \\
\text { thaw } \\
\text { (ng/ml) }\end{array}$ & RSD (\%) & $\begin{array}{c}\text { Long } \\
\text { stability } \\
\text { (ng/ml) }\end{array}$ & RSD (\%) \\
\hline \multirow[t]{3}{*}{ TSG } & $14,825.00$ & $14,588.47$ & 1.9 & 14,393 & 9.7 & $13,676.34$ & 5.0 & $14,032.10$ & 4.2 \\
\hline & 741.25 & 707.81 & 5.1 & 735.65 & 1.3 & 799.25 & 3.2 & 735.67 & 9.0 \\
\hline & 14.83 & 12.23 & 4.0 & 18.27 & 6.4 & 15.70 & 8.4 & 16.57 & 10.1 \\
\hline \multirow[t]{3}{*}{ Emodin } & $38,375.00$ & $18,338.88$ & 7.9 & $19,254.57$ & 5.0 & $16,020.76$ & 7.2 & $19,872.84$ & 11.6 \\
\hline & 767.50 & 783.9 & 6.7 & 773.62 & 2.4 & 703.82 & 11.0 & 723.65 & 9.1 \\
\hline & 15.28 & 15.38 & 3.8 & 12.28 & 7.0 & 17.00 & 9.1 & 12.72 & 5.3 \\
\hline \multirow[t]{3}{*}{ Aloe-emodin } & $2,900.00$ & $2,867.01$ & 6.1 & $3,021.55$ & 2.6 & $3,101.50$ & 1.7 & $2,756.34$ & 7.8 \\
\hline & 362.50 & 375.62 & 10.1 & 325.67 & 9.9 & 408.33 & 1.8 & 357.26 & 8.5 \\
\hline & 12.79 & 11.44 & 12.6 & 10.24 & 8.0 & 9.68 & 5.6 & 13.55 & 2.7 \\
\hline \multirow[t]{3}{*}{ Physcion } & $6,550.00$ & $6,258.35$ & 10.0 & 6,618.34 & 8.4 & $6,534.22$ & 6.3 & $6,896.46$ & 11.3 \\
\hline & 409.38 & 431.57 & 4.2 & 429.55 & 13.7 & 395.96 & 7.5 & 401.67 & 4.3 \\
\hline & 12.79 & 12.42 & 3.4 & 15.65 & 1.9 & 9.78 & 7.7 & 13.77 & 10.2 \\
\hline \multirow[t]{3}{*}{ E-glu } & $6,350.00$ & $6,025.12$ & 12.5 & 2054.33 & 11.8 & $6,202.46$ & 7.5 & $6,435.66$ & 13.9 \\
\hline & 396.88 & 366.48 & 8.7 & 366.16 & 2.6 & 409.91 & 10.8 & 394.13 & 12.3 \\
\hline & 12.40 & 13.19 & 6.1 & 15.22 & 9.3 & 11.32 & 11.4 & 11.58 & 11.9 \\
\hline \multirow[t]{3}{*}{ P-glu } & $1,233.30$ & $1,129.33$ & 7.8 & $1,238.43$ & 11.0 & $1,309.48$ & 14.9 & $1,286.72$ & 4.4 \\
\hline & 205.50 & 221.06 & 9.2 & 208.37 & 7.8 & 197.10 & 13.8 & 200.84 & 5.3 \\
\hline & 12.84 & 15.64 & 1.7 & 12.92 & 2.2 & 12.02 & 11.7 & 13.58 & 12.3 \\
\hline \multirow[t]{3}{*}{ Gallic acid } & $1,280.00$ & $1,342.38$ & 11.9 & $1,272.02$ & 13.8 & $1,188.50$ & 12.9 & $1,306.35$ & 7.9 \\
\hline & 213.32 & 278.94 & 4.7 & 277.25 & 12.2 & 199.66 & 7.6 & 201.39 & 8.3 \\
\hline & 13.32 & 13.56 & 11.5 & 12.82 & 8.9 & 11.38 & 4.9 & 14.12 & 6.6 \\
\hline \multirow[t]{3}{*}{ Catechin } & $4,750.00$ & $4,650.67$ & 4.6 & $4,654.36$ & 11.6 & 4,999.10 & 11.6 & $4,726.31$ & 6.7 \\
\hline & 296.87 & 301.23 & 6.4 & 277.48 & 9.3 & 302.41 & 7.0 & 286.34 & 10.6 \\
\hline & 18.56 & 18.06 & 9.7 & 17.90 & 4.2 & 18.6 & 2.9 & 20.9 & 5.2 \\
\hline \multirow[t]{3}{*}{ Resveratrol } & $8,600.00$ & $8,738.41$ & 6.8 & $8,654.18$ & 1.4 & 8,399.20 & 11.5 & $8,513.48$ & 2.4 \\
\hline & 537.50 & 521.81 & 4.4 & 542.29 & 1.9 & 501.81 & 6.6 & 514.25 & 1.5 \\
\hline & 16.78 & 16.28 & 8.8 & 15.64 & 8.8 & 18.84 & 7.3 & 15.34 & 6.7 \\
\hline
\end{tabular}

$\infty)$ values of emodin, physcion, and E-Glu decreased by 55.98 , 49.77 and $8.25 \%$, respectively, the Cmax values decreased by $85.18,29.48$, and $22.98 \%$, respectively.

As the common drugs contain $-\mathrm{OH},-\mathrm{COOH}$, and $-\mathrm{SH}$ groups, the primary way of metabolism in vivo is to combine these radicals with endogenous $\alpha$-D-glucuronide to produce $\beta$ glucuronide. PM mainly contains stilbene glycosides, anthraquinones, tannins and other components, as shown in Figure 1, which cintain multiple -OH radicals. For example, TSG (Sun, 2004; Lv et al., 2011b) and emodin are reported to metabolize glucuronidation in vivo. The metabolic pathway of these compounds are related to the metabolic pathway in bilirubin, which may affect the key enzymes and transporters of bilirubin metabolism (Yi et al., 2018). Therefore, it is essential to study these metabolites metabolism in vivo. Accordingly, we used biological enzymolysis combined with UHPLC-MS/MS technology to detect these compounds. After sulfatase-aided enzymolysis, all the phase II metabolites could transform into their prototypes. The specific contents of the phase II metabolites of these components were detected indirectly by evaluating the content difference of their prototypes in samples before and after enzymolysis. By considering the difference in the content of their prototypes in those conditions, we can indirectly determine whether these components had phase II metabolism and the specific content.

The pharmacokinetic curves of phase II metabolites are illustrated in Figure 5B. Resveratrol was immediately and completely transformed into phase II metabolites. After sulfatase-aided enzymolysis, the $\operatorname{AUC}(0-\infty)$ and $\mathrm{Cmax}$ values in $\mathrm{CCl}_{4}$ group were significantly higher than that in normal group $(p<0.05)$, while its metabolism in ANIT group was significantly inhibited. The trends of $\operatorname{AUC}(0-\infty)$ and Cmax of TSG in different models were consistent with the prototype, and emodin exhibited a similar pattern. The AUC $(0-\infty)$ and Cmax values of II phase metabolite of TSG were the highest in the ANIT model, and increased by $2,943.73 \%$ and $1917.18 \%$ respectively compared with the normal group; the AUC $(0-\infty)$ and Cmax values of emodin II phase metabolites were the highest in the $\mathrm{CCl}_{4}$ group, and increased by 522.45 and $250.27 \%$, respectively, when compared with the normal group.

\section{Metabolic Enzyme and Transporters Expression in Rat Liver}

The expression levels of metabolic enzyme and transporters in the rat livers were used to evaluate the liver status of rats in different pathological models. The quantitative results of the metabolic enzyme UGT1A1 and the nine transporters (MRP2, BSEP, OCT1, NTCP, MATE1, MDR1, OATP1A1, OATP1A2, and OATP1A4) are listed in Figure 6. The downregulation of BSEP and MRP2 expression is a major indicator of cholestasis (Yi et al., 2018). Before administration of AE-PM, the BSEP and MRP2 expression 


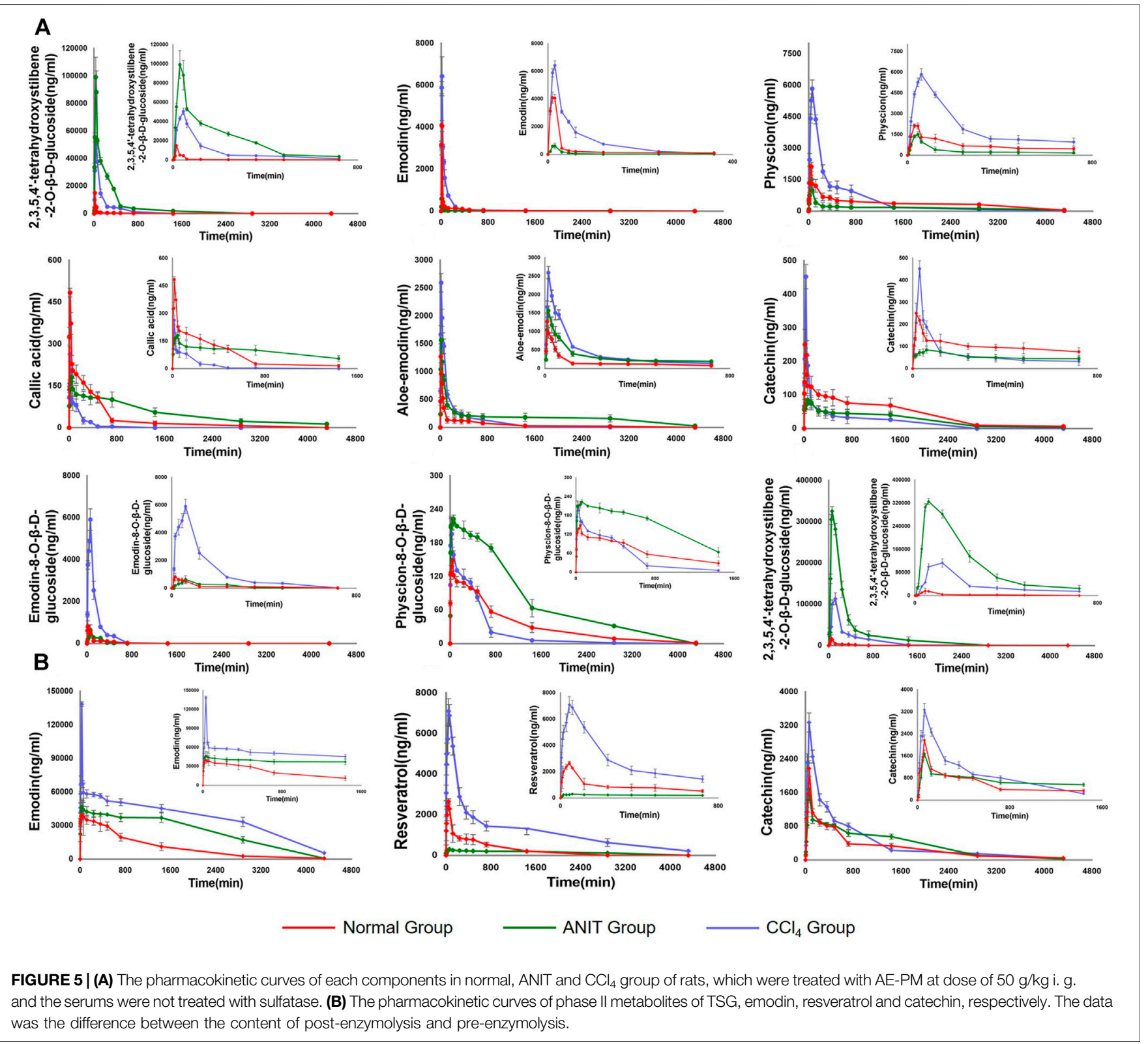

levels in ANIT group were significantly reduced by 38.15 and $47.90 \%$, respectively, when compared with the control group, indicating that ANIT-induced cholestasis had been successfully established in this pathological experiment. Furthermore, UGT1A1, OCT1, NTCP, MDR1, OATP1A2 and OATP1A4 of this model group decreased significantly by $38.22,62.92,38.02,72.37 \%, 24.28$, and $42.58 \%(p<0.05)$, respectively, when compared with the control group. Although the mechanism of $\mathrm{CCl}_{4}$-induced liver injury was significantly different from that of ANIT, it also showed a more obvious inhibitory effect on the expression levels of liver metabolic enzymes and transporters. Compared with the control group, the expression levels of UGT1A1, BSEP,
OATP1A4, OCT1, NTCP and MDR1 were reduced by 31.18 , $26.92,46.11,22.30,15.75$, and $34.15 \%$, respectively $(p<0.05)$.

\section{Correlation Between Area Under The Curve Values and Expression Levels of Metabolic Enzyme and Transporters}

The area under the curve (AUC) is an important indicator to evaluate the degree of drug absorption, reflecting the exposure characteristics of the drug in vivo. The critical enzymes and transporters located on the hepatocyte membrane are involved in the uptake, transformation and excretion of endogenous or exogenous substances by the liver. To further investigate the 
TABLE 8 | Correlation results of AUC values with metabolic enzymes and transporters $\left({ }^{\star *} p<0.01,{ }^{*} p<0.05\right)$.

\begin{tabular}{|c|c|c|c|c|c|c|c|c|c|c|}
\hline \multirow[t]{2}{*}{ Component } & \multicolumn{10}{|c|}{ Correlation coefficient $\rho$} \\
\hline & UGT1A1 & BSEP & OATP1A4 & OCT1 & OATP1A2 & NTCP & MRP2 & MDR1 & OATP1A1 & MATE1 \\
\hline TSG-॥ & $-0.832^{\star \star}$ & $-0.854^{\star \star}$ & $-0.539^{\star}$ & $-0.879^{\star \star}$ & -0.461 & $-0.864^{\star \star}$ & $-0.757^{\star \star}$ & $-0.886^{\star \star}$ & $-0.836^{\star \star}$ & -0.332 \\
\hline Emodin-II & -0.504 & -0.479 & $-0.834^{\star \star}$ & -0.296 & 0.371 & -0.189 & -0.236 & -0.446 & -0.279 & 0.361 \\
\hline Resveratrol-II & 0.418 & 0.357 & -0.109 & 0.489 & $0.718^{\star \star}$ & $0.579^{\star}$ & $0.529^{\star}$ & 0.450 & 0.496 & $0.825^{\star \star}$ \\
\hline Catechin-II & -0.436 & -0.489 & $-0.741^{\star \star}$ & -0.229 & 0.286 & -0.146 & -0.157 & -0.375 & -0.254 & 0.207 \\
\hline TSG & $-0.875^{\star \star}$ & $-0.932^{\star \star}$ & $-0.573^{\star}$ & $0.900^{\star \star}$ & -0.489 & $-0.804^{\star \star}$ & $-0.771^{\star \star}$ & $-0.911^{\star \star}$ & $-0.911^{\star \star}$ & -0.436 \\
\hline Emodin & 0.411 & 0.361 & -0.082 & 0.439 & $0.675^{\star \star}$ & $0.557^{\star}$ & $0.557^{\star}$ & 0.479 & $0.604^{*}$ & $0.832^{\star \star}$ \\
\hline E-glu & 0.186 & 0.129 & -0.204 & 0.179 & $0.571^{\star}$ & 0.468 & 0.282 & 0.218 & 0.361 & $0.625^{*}$ \\
\hline Physcion & 0.386 & 0.293 & -0.247 & 0.457 & $0.714^{\star \star}$ & $0.554^{*}$ & $0.539^{\star}$ & 0.379 & $0.514^{*}$ & $0.668^{\star *}$ \\
\hline P-glu & -0.354 & -0.300 & 0.181 & -0.486 & $-0.736^{\star \star}$ & $-0.536^{\star}$ & $-0.593^{\star}$ & -0.475 & $-0.532^{\star}$ & $-0.789^{\star *}$ \\
\hline Aloe-emodin & $-0.914^{\star *}$ & $-0.825^{\star \star}$ & $-0.702^{\star \star}$ & $-0.807^{\star \star}$ & -0.400 & $-0.754^{\star \star}$ & $-0.800^{\star \star}$ & $-0.936^{\star \star}$ & $-0.786^{\star \star}$ & -0.504 \\
\hline Catechin & 0.250 & 0.264 & $0.560^{\star}$ & 0.164 & -0.336 & -0.079 & 0.179 & 0.193 & -0.018 & $-0.561^{\star}$ \\
\hline Gallic acid & -0.439 & -0.354 & 0.145 & -0.446 & $-0.757^{\star \star}$ & $-0.525^{\star}$ & $-0.518^{*}$ & -0.443 & $-0.568^{\star}$ & $-0.850^{\star}$ \\
\hline
\end{tabular}
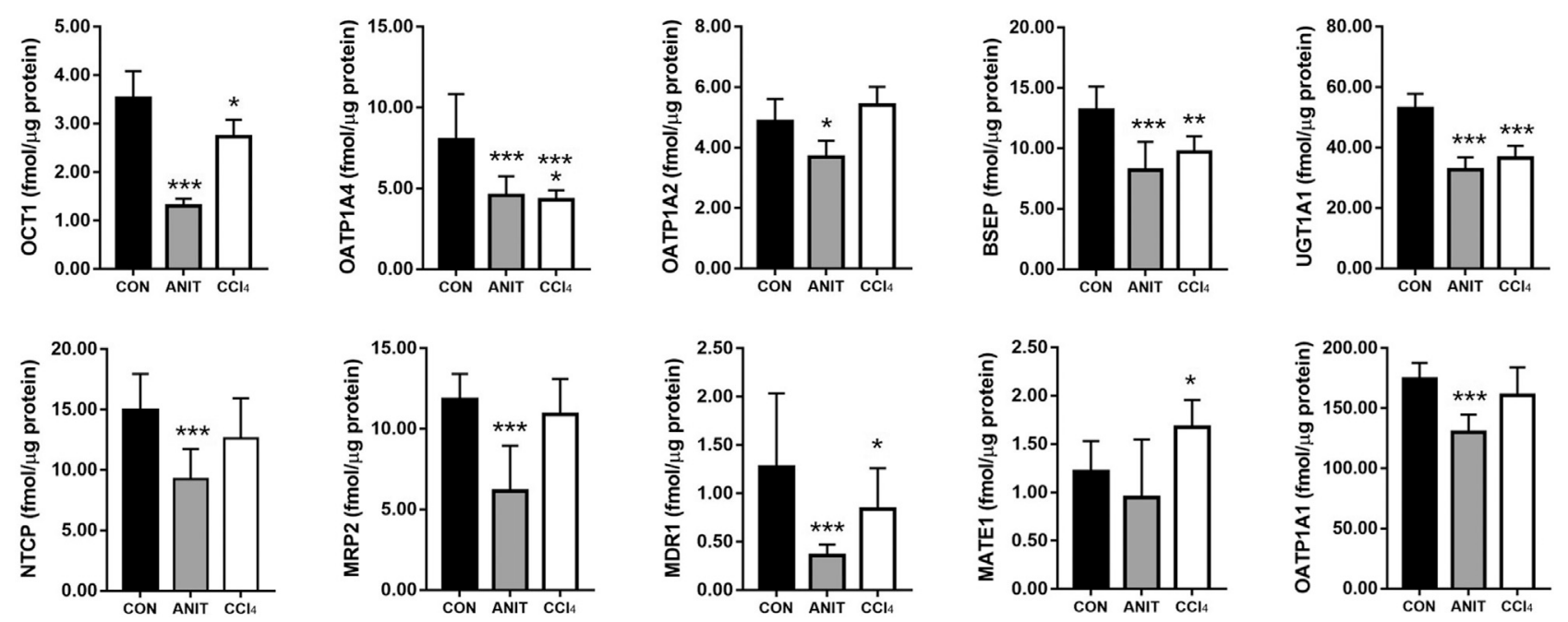

FIGURE 6 | The expression levels of metabolic enzyme UGT1A1 and nine transporters NTCP, OATP1A1, OATP1A2, OATP1A4, MDR1, BSEP, OCT1, MATE1, MRP2 in rat liver, respectively $\left({ }^{\star} p<0.05,{ }^{* \star} p<0.01\right.$ and ${ }^{* \star \star} p<0.001$ which compared with the control group).

reasons for the differences in the pharmacokinetics of PM in different liver pathological models, we made a correlation analysis between the AUC values of the active ingredients in PM and the expression levels of metabolic enzymes and transporters in the liver. The results are shown in Table 9, Supplementary Figures S1-S54.

The expression levels of UGT1A1 $(\rho=-0.832, \rho=-0.875, \rho=$ $-0.914), \operatorname{BSEP}(\rho=-0.854, \rho=-0.932, \rho=-0.825)$, OCT1 $(\rho=$ $-0.879, \rho=-0.900, \rho=-0.807)$ and MDR1 $(\rho=-0.886, \rho=-0.911$, $\rho=-0.936)(p<0.01)$ were significantly correlated with the exposure characteristics of TSG prototype and its phase II metabolites and aloe-emodin in vivo, respectively. In addition, the expression levels of NTCP, MRP2 and OATP1A1 were found in relation to the AUC values of TSG prototype $(\rho=-0.804, \rho=-0.771, \rho=-0.911)$ and its phase II metabolites $(\rho=-0.864, \rho=-0.757, \rho=-0.836)$, aloeemodin $(\rho=-0.754, \rho=-0.800, \rho=-0.786)(p<0.01)$, emodin $(\rho=$ $0.557, \rho=0.557, \rho=0.604)$, physcion $(\rho=0.554, \rho=0.539, \rho=0.514)$, P-Glu $(\rho=-0.536, \rho=-0.593, \rho=-0.532)$ and gallic acid $(\rho=-0.525$, $\rho=-0.518, \rho=-0.568)(p<0.05)$, respectively. And the expression levels of OATP1A2 and MATE1 significantly correlated with the AUC values of phase II metabolites of resveratrol $(\rho=0.718, \rho=$ $0.825)$, emodin $(\rho=0.675, \rho=0.832)$, physcion $(\rho=0.714, \rho=$ $0.668)$, P-Glu ( $\rho=-0.736, \rho=-0.789)$, gallic acid $(\rho=-0.757, \rho=$ $-0.850)(p<0.01)$ and E-Glu $(\rho=0.571, \rho=-0.625)(p<0.05)$. Besides, the expression levels of OATP1A4 were significantly correlated with the AUC values of aloe-emodin $(\rho=-0.702)$, the phase II metabolites of emodin $(\rho=-0.834)(p<0.01)$, the prototypes of TSG $(\rho=-0.573)$ and catechin $(\rho=0.560)(p<$ $0.05)$ and their phase II metabolites $(\rho=-0.539, \rho=-0.741)$ $(p<0.01)$.

\section{DISCUSSION}

PM-induced liver injury is limited by the cholestatic type, but also includes hepatocellular injury (Lianhong et al., 2015; Duan et al., 
TSG

Emodin

\begin{tabular}{|c|c|c|c|c|c|c|}
\hline & & & & & & \\
\hline & Normal group & ANIT group & $\mathrm{CCl}_{4}$ group & Normal group & ANIT group & $\mathrm{CCl}_{4}$ group \\
\hline AUC $(0-\infty)\left(\operatorname{ug} / L^{\star} h\right)$ & $12,860.002 \pm 1,267.111$ & $340,555.228 \pm 8,676.096^{* * *}$ & $116,021.02 \pm 3,800.387^{* * *}$ & $3,396.707 \pm 266.27$ & $1,495.195 \pm 99.774^{* * *}$ & $5,967.825 \pm 451.127^{* * *}$ \\
\hline 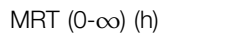 & $4.54 \pm 1.225$ & $6.031 \pm 1.926^{* *}$ & $3.4 \pm 1.039^{*+}$ & $6.093 \pm 1.83$ & $22.849 \pm 5.28^{*+*}$ & $1.234 \pm 0.681^{+*+*}$ \\
\hline $\mathrm{t} 1 / 2 \mathrm{z}(\mathrm{h})$ & $1.947 \pm 0.806$ & $2.606 \pm 0.612^{* *}$ & $2.806 \pm 0.878^{*}$ & $3.681 \pm 1.075$ & $3.913 \pm 0.821$ & $3.654 \pm 0.267$ \\
\hline $\operatorname{Tmax}(\mathrm{h})$ & $0.25 \pm 0.0293$ & $0.5 \pm 0.0278^{*+*}$ & $0.75 \pm 0.136^{*+* t}$ & $0.167 \pm 0.059$ & $0.25 \pm 0.063^{* *}$ & $0.25 \pm 0.0659^{* *}$ \\
\hline $\mathrm{Vz} / \mathrm{F}(\mathrm{L} / \mathrm{kg})$ & $4.369 \pm 0.711$ & $0.221 \pm 0.0206^{* * *}$ & $0.698 \pm 0.073^{*+*+}$ & $31.274 \pm 3.246$ & $75.533 \pm 8.863^{*+*+}$ & $68.125 \pm 6.027^{\text {t*t* }}$ \\
\hline $\mathrm{CL} / \mathrm{F}(\mathrm{L} / \mathrm{h} / \mathrm{kg})$ & $1.555 \pm 0.15$ & $0.059 \pm 0.008^{* *+}$ & $0.172 \pm 0.0484^{* \star *}$ & $5.888 \pm 1.3$ & $13.376 \pm 1.245^{\star \star \star \star}$ & $3.351 \pm 2.464^{* *}$ \\
\hline Cmax (ug/L) & $15,042.977 \pm 1,420.87$ & $99,300.972 \pm 1,092.408^{* * *}$ & $50,633.759 \pm 2,885.149^{* * * *}$ & $4,095.622 \pm 119.478$ & $606.742 \pm 29.949^{* * *+}$ & $6,430.985 \pm 552.673^{* * *}$ \\
\hline
\end{tabular}

\begin{tabular}{|c|c|c|c|}
\hline & \multicolumn{3}{|c|}{ E-glu } \\
\hline & Normal group & ANIT group & $\mathrm{CCl} 4$ group \\
\hline AUC $(0-\infty)($ ug/L*h) & $1878.279 \pm 537.5$ & $1723.354 \pm 169.583$ & $14,197.913 \pm 845.631^{*+*}$ \\
\hline 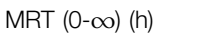 & $3.881 \pm 1.519$ & $2.813 \pm 0.872^{\text {t*t* }}$ & $2.437 \pm 1.173^{*+*}$ \\
\hline $\mathrm{t} 1 / 2 \mathrm{z}(\mathrm{h})$ & $3.92 \pm 0.219$ & $4.678 \pm 1.101^{* *}$ & $4.002 \pm 1.399$ \\
\hline $\operatorname{Tmax}(h)$ & $0.25 \pm 0.0301$ & $1 \pm 0.248^{*+* t}$ & $1 \pm 0.289^{*+*}$ \\
\hline $\mathrm{Vz} / \mathrm{F}(\mathrm{L} / \mathrm{kg})$ & $60.229 \pm 9.446$ & $78.332 \pm 4.397^{+*+t}$ & $8.135 \pm 1.747^{+* t+}$ \\
\hline $\mathrm{CL} / \mathrm{F}(\mathrm{L} / \mathrm{h} / \mathrm{kg})$ & $10.648 \pm 4.718$ & $11.605 \pm 2.029$ & $1.409 \pm 0.24$ \\
\hline Cmax (ug/L) & $821.44925 \pm 84.984$ & $632.694 \pm 49.957^{* * *}$ & $5,915.695 \pm 871.195^{* * t}$ \\
\hline
\end{tabular}

\begin{tabular}{|c|}
\hline Normal group \\
\hline $2,627.797 \pm 498.523$ \\
\hline $145.555 \pm 11.305$ \\
\hline $103.734 \pm 14.95$ \\
\hline $0.25 \pm 0.0234$ \\
\hline $237.077 \pm 18.348$ \\
\hline $1.584 \pm 0.27$ \\
\hline $251.047 \pm 11.768$ \\
\hline
\end{tabular}

\section{Catechin}

\section{Physcion}

\begin{tabular}{|c|c|c|c|c|c|c|}
\hline & Normal group & ANIT group & $\mathrm{CCl}_{4}$ group & Normal group & ANIT group & $\mathrm{CCl}_{4}$ group \\
\hline AUC $(0-\infty)\left(\mathrm{ug} / \mathrm{L}^{*} h\right)$ & $27,822.335 \pm 773.899$ & $13,974.221 \pm 624.579^{* *+*}$ & $35,958.959 \pm 528.665^{*+1}$ & $2,271.749 \pm 78.37$ & $7,052.215 \pm 315.03^{*+* t}$ & $1,449.713 \pm 82.063^{*+* x}$ \\
\hline 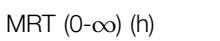 & $26.749 \pm 1.523$ & $37.577 \pm 2.271^{* *}$ & $10.042 \pm 1.144^{* * *}$ & $15.929 \pm 2.36$ & $18.829 \pm 3.363$ & $7.483 \pm 1.42^{\star \star}$ \\
\hline$t 1 / 2 z(h)$ & $16.979 \pm 1.869$ & $28.937 \pm 1.502^{* * *}$ & $8.78 \pm 1.604^{*+*}$ & $11.252 \pm 1.851$ & $3.224 \pm 0.473^{*+* t}$ & $4.085 \pm 0.453^{*+*+}$ \\
\hline $\operatorname{Tmax}(\mathrm{h})$ & $0.5 \pm 0.094$ & $0.75 \pm 0.0238^{* *}$ & $1 \pm 0.0675^{* * *}$ & $0.75 \pm 0.049$ & $1 \pm 0.232^{* *}$ & $0.25 \pm 0.0661^{* *+}$ \\
\hline $\mathrm{Vz} / \mathrm{F}(\mathrm{L} / \mathrm{kg})$ & $17.612 \pm 2.411$ & $59.761 \pm 3.407^{*+*}$ & $7.047 \pm 1.106^{*+*}$ & $142.94 \pm 11.136$ & $13.195 \pm 1.861^{*+*}$ & $81.316 \pm 5.01^{* *}$ \\
\hline $\mathrm{CL} / \mathrm{F}(\mathrm{L} / \mathrm{h} / \mathrm{kg})$ & $0.719 \pm 0.0478$ & $1.431 \pm 0.494^{*+*}$ & $0.556 \pm 0.085^{\star}$ & $8.804 \pm 0.88$ & $2.836 \pm 0.596^{*+*}$ & $13.796 \pm 0.503^{* *}$ \\
\hline \multirow[t]{3}{*}{ Cmax (ug/L) } & $2,135.037 \pm 55.906$ & $1,505.553 \pm 16.353^{* * *}$ & $5,844.122 \pm 36.939^{* * *}$ & $148.403 \pm 8.946$ & $222.994 \pm 13.243^{* *}$ & $211.025 \pm 3.041^{* *}$ \\
\hline & \multicolumn{3}{|c|}{ Aloe-emodin } & \multicolumn{3}{|c|}{ Gallic acid } \\
\hline & Normal group & ANIT group & $\mathrm{CCl}_{4}$ group & Normal group & ANIT group & $\mathrm{CCl}_{4}$ group \\
\hline AUC $(0-\infty)($ ug/L*h) & $3,563.013 \pm 34.244$ & $41,745.244 \pm 693.83^{\text {t*t }}$ & $6,619.038 \pm 344.087^{* *+}$ & $2,774.695 \pm 59.062$ & $6,502.744 \pm 59.616^{* * t}$ & $436.565 \pm 9.708^{* *+}$ \\
\hline MRT $(0-\infty)(h)$ & $13.988 \pm 1.42$ & $198.2 \pm 3.166^{*+* t}$ & $6.469 \pm 0.422^{* *}$ & $12.834 \pm 1.023$ & $55.689 \pm 4.221^{* * * t}$ & $3.064 \pm 0.12^{*+*+}$ \\
\hline $\mathrm{t} 1 / 2 \mathrm{z}(\mathrm{h})$ & $3.545 \pm 0.185$ & $139.843 \pm 8.294^{*+* t}$ & $3.448 \pm 0.177$ & $19.71 \pm 0.891$ & $37.733 \pm 4.056^{* *}$ & $4.695 \pm 0.509^{* *}$ \\
\hline $\operatorname{Tmax}(h)$ & $0.167 \pm 0.051$ & $0.25 \pm 0.032^{* *}$ & $0.25 \pm 0.052^{* *}$ & $0.25 \pm 0.0728$ & $0.75 \pm 0.0231^{*+* t}$ & $0.25 \pm 0.0641$ \\
\hline $\mathrm{Vz} / \mathrm{F}(\mathrm{L} / \mathrm{kg})$ & $28.711 \pm 1.55$ & $96.678 \pm 8.349^{*+*}$ & $15.032 \pm 1.204^{*}$ & $205.009 \pm 2.203$ & $167.465 \pm 6.197^{* *}$ & $310.403 \pm 9.634^{4+*}$ \\
\hline $\mathrm{CLZ} / \mathrm{F}(\mathrm{L} / \mathrm{h} / \mathrm{kg})$ & $5.613 \pm 0.385$ & $0.479 \pm 0.074^{4 * * *}$ & $3.022 \pm 0.826^{* *}$ & $7.208 \pm 0.841$ & $3.076 \pm 0.35^{*+*}$ & $45.812 \pm 2.249^{*+*}$ \\
\hline Cmax (ug/L) & $1,272.720 \pm 70.28$ & $1,569.070 \pm 47.023$ & $2,598.319 \pm 41.816^{*+*}$ & $484.264 \pm 9.872$ & $181.248 \pm 5.001^{* * *}$ & $263.718 \pm 2.794^{* *}$ \\
\hline
\end{tabular}

\begin{tabular}{|c|c|c|c|c|c|c|}
\hline & Normal group & ANIT group & $\mathrm{CCl}_{4}$ group & Normal group & ANIT group & $\mathrm{CCl}_{4}$ group \\
\hline 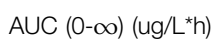 & $27,822.335 \pm 773.899$ & $13,974.221 \pm 624.579^{* *+*}$ & $35,958.959 \pm 528.665^{\text {t.*t }}$ & $2,271.749 \pm 78.37$ & $7,052.215 \pm 315.03^{* * *}$ & $1,449.713 \pm 82.063^{*+*+}$ \\
\hline 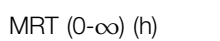 & $26.749 \pm 1.523$ & $37.577 \pm 2.271^{* *}$ & $10.042 \pm 1.144^{* * *}$ & $15.929 \pm 2.36$ & $18.829 \pm 3.363$ & $7.483 \pm 1.42^{* *}$ \\
\hline$t 1 / 2 z(h)$ & $16.979 \pm 1.869$ & $28.937 \pm 1.502^{* * * t}$ & $8.78 \pm 1.604^{*+* t}$ & $11.252 \pm 1.851$ & $3.224 \pm 0.473^{*+*}$ & $4.085 \pm 0.453^{*+* t}$ \\
\hline $\operatorname{Tmax}(\mathrm{h})$ & $0.5 \pm 0.094$ & $0.75 \pm 0.0238^{* *}$ & $1 \pm 0.0675^{* * *+}$ & $0.75 \pm 0.049$ & $1 \pm 0.232^{* *}$ & $0.25 \pm 0.0661^{* * * t}$ \\
\hline $\mathrm{Vz} / \mathrm{F}(\mathrm{L} / \mathrm{kg})$ & $17.612 \pm 2.411$ & $59.761 \pm 3.407^{* * *}$ & $7.047 \pm 1.106^{* * *}$ & $142.94 \pm 11.136$ & $13.195 \pm 1.861^{* * *}$ & $81.316 \pm 5.01^{* *}$ \\
\hline $\mathrm{CL} / \mathrm{F}(\mathrm{L} / \mathrm{h} / \mathrm{kg})$ & $0.719 \pm 0.0478$ & $1.431 \pm 0.494^{+3 * t}$ & $0.556 \pm 0.085^{\star}$ & $8.804 \pm 0.88$ & $2.836 \pm 0.596^{* * *}$ & $13.796 \pm 0.503^{* *}$ \\
\hline \multirow[t]{3}{*}{ Cmax (ug/L) } & $2,135.037 \pm 55.906$ & $1,505.553 \pm 16.353^{* * *+}$ & $5,844.122 \pm 36.939^{* * *}$ & $148.403 \pm 8.946$ & $222.994 \pm 13.243^{* *}$ & $211.025 \pm 3.041^{* *}$ \\
\hline & \multicolumn{3}{|c|}{ Aloe-emodin } & \multicolumn{3}{|c|}{ Gallic acid } \\
\hline & Normal group & ANIT group & $\mathrm{CCl}_{4}$ group & Normal group & ANIT group & $\mathrm{CCl}_{4}$ group \\
\hline 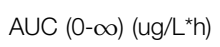 & $3,563.013 \pm 34.244$ & $41,745.244 \pm 693.83^{* *+*}$ & $6,619.038 \pm 344.087^{* *+}$ & $2,774.695 \pm 59.062$ & $6,502.744 \pm 59.616^{* * t}$ & $436.565 \pm 9.708^{* * *}$ \\
\hline 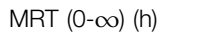 & $13.988 \pm 1.42$ & $198.2 \pm 3.166$ & $6.469 \pm 0.422^{* *}$ & $12.834 \pm 1.023$ & $55.689 \pm 4.221^{* \star * t}$ & $3.064 \pm 0.12^{* *+*}$ \\
\hline$t 1 / 2 z(h)$ & $3.545 \pm 0.185$ & $139.843 \pm 8.294^{*+* t}$ & $3.448 \pm 0.177$ & $19.71 \pm 0.891$ & $37.733 \pm 4.056^{* *}$ & $4.695 \pm 0.509^{* *}$ \\
\hline $\operatorname{Tmax}(\mathrm{h})$ & $0.167 \pm 0.051$ & $0.25 \pm 0.032^{* *}$ & $0.25 \pm 0.052^{* *}$ & $0.25 \pm 0.0728$ & $0.75 \pm 0.0231^{* * *}$ & $0.25 \pm 0.0641$ \\
\hline $\mathrm{Vz} / \mathrm{F}(\mathrm{L} / \mathrm{kg})$ & $28.711 \pm 1.55$ & $96.678 \pm 8.349^{*+*}$ & $15.032 \pm 1.204^{*}$ & $205.009 \pm 2.203$ & $167.465 \pm 6.197^{* *}$ & $310.403 \pm 9.634$ \\
\hline $\mathrm{CL} / \mathrm{F}(\mathrm{L} / \mathrm{h} / \mathrm{kg})$ & $5.613 \pm 0.385$ & $0.479 \pm 0.074^{* \star \star}$ & $3.022 \pm 0.826$ & $7.208 \pm 0.841$ & $3.076 \pm 0.35^{*+*}$ & $45.812 \pm 2.249^{+*+*}$ \\
\hline Cmax (ug/L) & $1,272.720 \pm 70.28$ & $1,569.070 \pm 47.023$ & $2,598.319 \pm 41.816^{* * t}$ & $484.264 \pm 9.872$ & $181.248 \pm 5.001^{* * *}$ & $263.718 \pm 2.794^{* *}$ \\
\hline
\end{tabular}

\section{ANIT group}

CCl4 group

\begin{tabular}{|c|c|}
\hline $11,568.084 \pm 195.158^{* *}$ & $1,502.738 \pm 140.965^{* * *}$ \\
\hline $252.563 \pm 3.754^{4+*}$ & $11.218 \pm 1.227^{\text {tat }}$ \\
\hline $177.313 \pm 1.093^{* *}$ & $3.757 \pm 0.816^{* *}$ \\
\hline $1 \pm 0.742^{*+*}$ & $0.5 \pm 0.0408^{*+*}$ \\
\hline $442.359 \pm 16.868^{*+* t}$ & $72.16 \pm 12.592^{*+* t}$ \\
\hline $1.729 \pm 0.229$ & $13.309 \pm 1.754^{* \ldots+t}$ \\
\hline $84.472 \pm 8.848^{*+*}$ & $452.775 \pm 8.941^{* * t}$ \\
\hline
\end{tabular}

P-glu

(Continued on following page) 


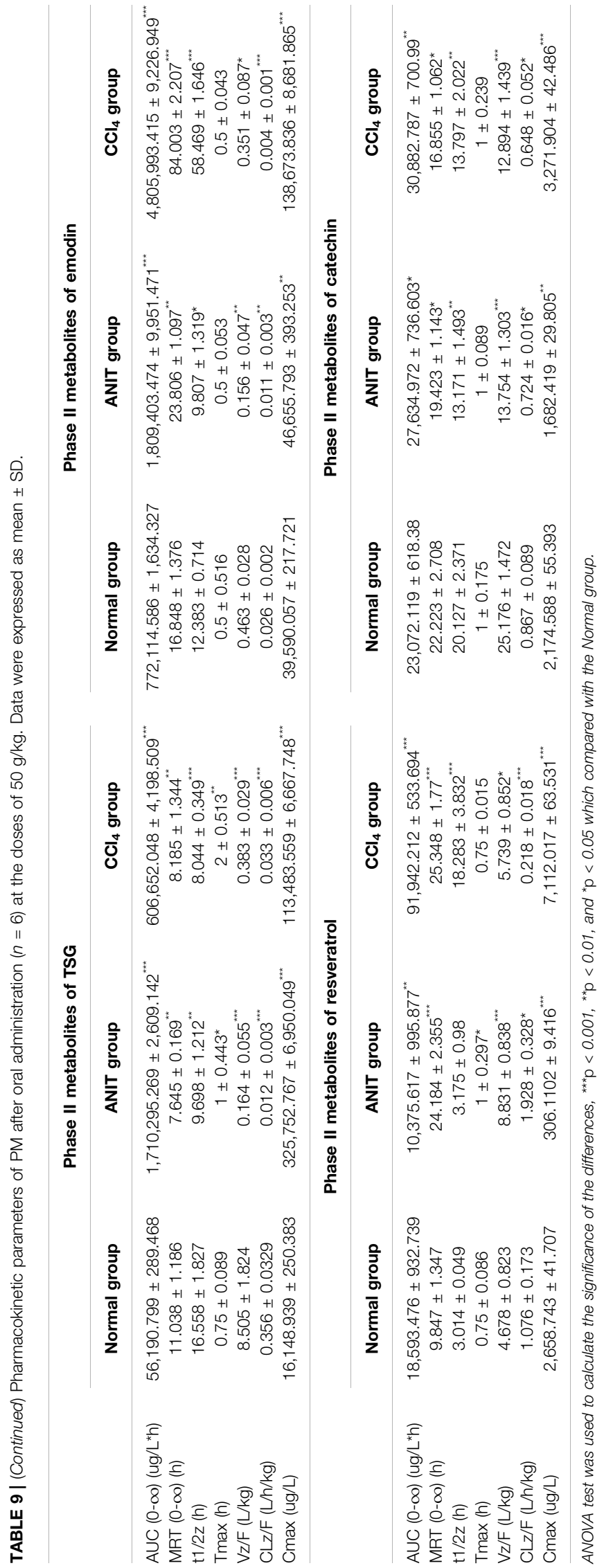

2020; Yamakawa et al., 2020). In the present study, ANIT and $\mathrm{CCl}_{4}$ were used as models of clinical liver injury. ANIT is a common inducer of intrahepatic cholestasis experimental models and induce cholestasis by destroying the bile duct epithelial cells and hepatocytes. Bile duct obstruction, severe apoptosis or necrosis of interlobular duct epithelial cells are characteristics of ANIT, and most prominent $24-48 \mathrm{~h}$ after model induction. TBIL and DBIL in the serum were significantly increased, the expression levels of the bilirubin metabolizing enzymes UGT1A1 and transporters OATP2, MRP2 and BSEP were notably suppressed (Li et al., 2016; Yi et al., 2018). $\mathrm{CCl}_{4}$ is a chemical inducer of liver injury, mainly through the formation of free radicals, triggering chain reactions of peroxidation induced by hepatocyte damage (Shuwen and Zhen, 2019). It is featured by coagulative necrosis in the central region of the hepatic lobules and vacuolar degeneration in the surrounding hepatocytes (Xiaohui et al., 2018), with markedly elevated expression levels of ALT and AST (Lianhong et al., 2015). The results of serum biochemical and histopathological examinations showed that the models of ANIT and $\mathrm{CCl}_{4}$ were successfully achieved.

The pharmacokinetic characteristics of the nine components of AE-PM were studied by using UPLC-MS/MS. The sulfatase hydrolysis technique was used for the indirect determination of phase II metabolites of TSG, emodin, resveratrol and catechins. Physcion also undergoes glucuronidation and sulfation, consistent with the results of the Zhang J.' study (Zhang et al., 2018a), but the levels of conjugates were too low to allow pharmacokinetic analysis. Prototype of resveratrol cannot be detected in all three groups before hydrolysis, indicating that it is mainly presented in glucuronic acid and sulfuric acid conjugation. Resveratrol was not detected in the plasma of PM (before and after concoction) in Zhang L.' study (Zhang et al., 2013). 81.36, 83.39, and 83.95\% TSG, 99.56, 99.92, and $99.88 \%$ emodin, $64.63,70.49$, and $95.36 \%$ catechin exist in normal, ANIT and $\mathrm{CCl}_{4}$ groups in the form of the phase II metabolites. The AUC $(0-\infty)$ values of phase II metabolite of resveratrol in control, ANIT, and $\mathrm{CCl}_{4}$ groups were 18,593.48, 10,375.62, and $91,942.21 \mu \mathrm{g} / \mathrm{L}$, respectively. The conversion rates of phase II metabolites of TSG and emodin among the three groups did not present significant differences. However, overall, the exposure levels of phase II metabolites of TSG and emodin were higher in both pathological models. Catechins and resveratrol were more inclined to undergo phase II metabolism in the $\mathrm{CCl}_{4}$ model. However, the expression level of UGT1A1 involved in phase II metabolism was significantly inhibited in ANIT and $\mathrm{CCl}_{4}$ models. It is possible that the drug might be more susceptible to phase II metabolism due to the compensatory increase of UGT1A1 in both pathological models.

The Tmax value of phase II metabolite of TSG in $\mathrm{CCl}_{4}$ models was $120 \mathrm{~min}$, to the other components in the different groups were less than $60 \mathrm{~min}$. Aloe-emodin, emodin prototype and its II phase metabolite presented Tmax values smaller than $30 \mathrm{~min}$, indicating that these components absorbed rapidly. The AUC(0$\infty)$ and Cmax values of the TSG prototype and its phase II metabolites were higher in the ANIT model, followed by $\mathrm{CCl}_{4}$ 
group, and the normal group. These two components had higher exposure and slower elimination in both pathological states. The AUC $(0-\infty)$ and Cmax values of emodin, physcion, phase II metabolites of emodin, and resveratrol were higher in the $\mathrm{CCl}_{4}$ model, followed by the normal group and the ANIT group. The liver cell damage caused by $\mathrm{CCl}_{4}$ would promote their absorption into the blood and inhibit its elimination, while cholestasis could hinder the absorption. Aloe-emodin had higher exposure and slower elimination in ANIT group. Catechins and P-Glu could be rapidly absorbed and eliminated in the $\mathrm{CCl}_{4}$ model, but cholestasis could inhibit their elimination. The absorption and elimination of gallic acid could be inhibited in the case of cholestasis. The phase II metabolite of catechin could be absorbed and eliminated rapidly in the normal group but inhibited in ANIT and $\mathrm{CCl}_{4}$. The exposure levels of physcion, emodin, E-Glu, phase II metabolites of emodin and catechin were higher in $\mathrm{CCl}_{4}$-induced pathological state. In contrast TSG, aloeemodin, gallic acid and the phase II metabolite of TSG were higher in the cholestasis state.

There was a correlation between the exposure characteristics of the active ingredients in PM and the expression levels of liver metabolizing enzymes and transporters, with TSG and aloeemodin being the most pronounced. The AUC values of TSG and aloe-emodin showed a significant negative correlation with the expression levels of UGT1A1, BSEP, OATP1A4, OCT1, NTCP, MRP2, and MDR1. This result suggests that the metabolisms of TSG and aloe-emodin by the liver were weakened when metabolic enzymes and transporters were inhibited, resulting in the elevated occurrence of TSG and aloe-emodin in the blood. The AUC values of emodin, physcion, and resveratrol were positively correlated with the expression levels of OATP1A2, NTCP, and MRP2, suggesting that the excretions of emodin, physcion and resveratrol were promoted when the expression levels of OATP1A2, NTCP, and MRP2 were reduced. Besides, the expression levels of UGT1A1 decreased in normal rats, while the expression levels of UGT1A1, MATE1, BSEP, and OCT1 increased in the ANIT and $\mathrm{CCl}_{4}$ groups after administration of AE-PM for $72 \mathrm{~h}$, compared with those when AE-PM was not administered. Our results might suggest that PM could upregulate the expression levels of bilirubin metabolizing enzymes and transporters in injured liver and downregulate them in the normal liver. Finally, the mechanism of hepatic metabolizing enzymes and transporters that affect the metabolism of the active ingredients in PM needs further investigation.

\section{CONCLUSION}

A more comprehensive description of the pharmacokinetics of PM was investigated. The phase II metabolites TSG, emodin, resveratrol and catechin were preliminarily analyzed. In addition, a priliminary correlation analysis of the expression levels of hepatic metabolizing enzymes and transporters with the pharmacokinetic parameters of PM was done in this work. At the same time, the specific mechanisms of the interaction between these two variables that affect each other still needs further experimental investigation.

\section{DATA AVAILABILITY STATEMENT}

The original contributions presented in the study are included in the article/Supplementary Material, further inquiries can be directed to the corresponding authors.

\section{ETHICS STATEMENT}

The animal study was reviewed and approved by the Institutional Animal Committee of Shanghai University of Traditional Chinese Medicine.

\section{AUTHOR CONTRIBUTIONS}

TZ and YD formulated the study concept and design of this paper, guided the critical revision of the manuscript and provide important intellectual content. NM performed the research, acquired and analyzed the data, drafted the manuscript. YuZ and Yoz helped in executing part of research. LS improved the manuscript. All the authors have reviewed the manuscript, agreed to all the contents and agreed the submission.

\section{FUNDING}

We gratefully acknowledge the financial support by program of the National Natural Science Foundation of China (grant numbers 81872981); "Shuguang Program" supported by Shanghai Education Development Foundation and Shanghai Municipal Education Commission (grant numbers 20SG43); the National Scientific and Technological Major Special Project of China (grant number 2019ZX09201004-002); the Key project of Shanghai 3-year plan (ZY(2018-2020)-CCCX2001-04); projects sponsored by the development fund for Shanghai Talents (grant number 2018105); and a project of the Shanghai Committee of Science and Technology (grant number 20S21902500); project of the Shanghai Municipal Commission of Health and Family Planning (grant number 2017YQ072); program of Shanghai Leading Talents (grant number 2019100); the Innovation activity plan for College Students of SHUTCM (grant number 2020SHUTCM131).

\section{SUPPLEMENTARY MATERIAL}

The Supplementary Material for this article can be found online at: https://www.frontiersin.org/articles/10.3389/fphar.2021.655332/ full\#supplementary-material 


\section{REFERENCES}

Byeon, J.-H., Kil, J.-H., Ahn, Y.-C., and Son, C.-G. (2019). Systematic Review of Published Data on Herb Induced Liver Injury. J. Ethnopharmacology 233, 190-196. doi:10.1016/j.jep.2019.01.006Epub 2019/01/15PubMed PMID: 30639232

Chang, M.-L., Yeh, C-T., Chang, P-Y., and Chen, J-C. (2005). Comparison of Murine Cirrhosis Models Induced by Hepatotoxin Administration and Common Bile Duct Ligation. Wjg 11 (27), 4167-4172. doi:10.3748/wjg.v11. i27.4167PubMed PMID: WOS:000208103400006

Commission Cp (2020). PHARMACOPOEIA OF THE PEOPLE'S REPUBLIC OF CHINA. Bei Jing: China Medical Science Press.

Ding, Y., Zhang, T., Tao, J.-S., Tan, B., Guo, C.-R., and Yang, L. (2012). HPLC-MS/MS Method to Determine Genipin in Rat Plasma after Hydrolysis with Sulfatase and its Application to a Pharmacokinetic Study. Biomed. Chromatogr. 26 (7), 816-825. doi:10.1002/bmc. 1735PubMed PMID: 22113875

Dong, H., Slain, D., Cheng, J., Ma, W., and Liang, W. (2014). Eighteen Cases of Liver Injury Following Ingestion of Polygonum Multiflorum. Complement. Therapies Med. 22 (1), 70-74. doi:10.1016/j.ctim.2013.12.008Epub 2014/02/ 25PubMed PMID: 24559819

Duan, Z., Zhang, Y., Zhu, C., Wu, Y., Du, B., and Ji, H. (2020). Structural Characterization of Phosphorylated Pleurotus Ostreatus Polysaccharide and its Hepatoprotective Effect on Carbon Tetrachloride-Induced Liver Injury in Mice. Int. J. Biol. Macromolecules 162, 533-547. doi:10.1016/j.ijbiomac.2020.06. 107Epub 2020/06/23PubMed PMID: 32565302

Hagenbuch, B. (2007). Cellular Entry of Thyroid Hormones by Organic Anion Transporting Polypeptides. Best Pract. Res. Clin. Endocrinol. Metab. 21 (2), 209-221. doi:10.1016/j.beem.2007.03.004Epub 2007/06/19PubMed PMID: 17574004

Hoekstra, L. T., de Graaf, W., Nibourg, G. A. A., Heger, M., Bennink, R. J., Stieger, B., et al. (2013). Physiological and Biochemical Basis of Clinical Liver Function Tests. Ann. Surg. 257 (1), 27-36. doi:10.1097/SLA.0b013e31825d5d47Epub 2012/07/28PubMed PMID: 22836216

Jung, K. A., Min, H. J., Yoo, S. S., Kim, H. J., Choi, S. N., Ha, C. Y., et al. (2011). Drug-Induced Liver Injury: Twenty Five Cases of Acute Hepatitis Following Ingestion of Polygonum Multiflorum Thunb. Gut Liver 5 (4), 493-499. doi:10.5009/gnl.2011.5.4.493Epub 2011/12/24PubMed PMID: 22195249; PubMed Central PMCID: PMCPMC3240794

Faber, K. N., Müller, M., and Jansen, P. L. M. (2003). Drug Transport Proteins in the Liver. Adv. Drug Deliv. Rev. 55 (1), 107-124. doi:10.1016/s0169-409x(02) 00173-4

Lan-zhi, H., Ping, Y., Ya-kun, M., Zhen-fang, Z., Hui-min, L., He-rong, C., et al. (2017). Study on the Mechanism of PPAR- $\gamma$ Dependent Immunological Idiosyncrasy Liver Injury Induced by Polygonum Multiflorum. Acta Pharmaceutica Sinica 52 (7), 1027-1032. doi:10.16438/j.0513-4870.2016-0774

Li, C. (2015). Preliminary Study on Heterogenous Liver Injury of Polygonum Multiflorum Based on Immune Stress. Chengdu: Chengdu University of Traditional Chinese Medicine.

Li, C., Rao, T., Chen, X., Zou, Z., Wei, A., Tang, J., et al. (2019). HLA-B³5:01Allele Is a Potential Biomarker for PredictingPolygonum Multiflorum-Induced Liver Injury in Humans. Hepatology 70 (1), 346-357. doi:10.1002/hep.30660Epub 2019/04/16PubMed PMID: 30985007

Li, D.-K., Chen, J., Ge, Z.-Z., and Sun, Z.-X. (2017). Hepatotoxicity in Rats Induced by Aqueous Extract of Polygoni Multiflori Radix, Root of Polygonum Multiflorum Related to the Activity Inhibition of CYP1A2 or CYP2E1. Evidence-Based Complement. Altern. Med. 2017, 1-11. doi:10.1155/2017/ 9456785Epub 2017/06/20PubMed PMID: 28626488; PubMed Central PMCID: PMCPMC5463189

Li, X., Liu, R., Yu, L., Yuan, Z., Sun, R., Yang, H., et al. (2016). Alphanaphthylisothiocyanate Impairs Bile Acid Homeostasis through AMPK-FXR Pathways in Rat Primary Hepatocytes. Toxicology 370, 106-115. doi:10.1016/j. tox.2016.09.020

Lianhong, Y., Hao, Y., and Jingyong, P. (2015). Molecular Mechanism and Intervention of Chinese Medicine of Carbon Tetrachloride Induced Liver Injury. China J. Mod. Appl. Pharm. 32 (9), 1147-1155. doi:10.13748/j.cnki. issn1007-7693.2015.09.031
Lin, L., Lin, H., Yin, X., Zhao, Y., Xia, Z., Zhang, M., et al. (2015). Characterization of the Constituents in Rat Plasma after Oral Administration of Radix Polygoni Multiflori Extracts by Ultra-performance Liquid Chromatography/quadrupole Time-Of-Flight Mass Spectrometry. Biomed. Chromatogr. 29 (10), 1541-1547. doi:10.1002/bmc.3456Epub 2015/03/27PubMed PMID: 25807921

Lin, L., Ni, B., Lin, H., Cao, S., Yang, C., Zhao, Y., et al. (2015). Simultaneous Determination and Pharmacokinetic Study of P-Hydroxybenzaldehyde, 2,3,5,4'Tetrahydroxystilbene-2-O- $\beta$-Glucoside, Emodin-8-O- $\beta$-D-Glucopyranoside, and Emodin in Rat Plasma by Liquid Chromatography Tandem Mass Spectrometry after Oral Administration of Polygonum Multiflorum. Anal. Methods 7 (1), 244-252. doi:10.1039/c4ay02197e

Liu, Y., Wang, W., Sun, M., Ma, B., Pang, L., Du, Y., et al. (2019). Polygonum Multiflorum-Induced Liver Injury: Clinical Characteristics, Risk Factors, Material Basis, Action Mechanism and Current Challenges. Front. Pharmacol. 10, 1467. doi:10.3389/fphar.2019.01467Epub 2020/01/11PubMed PMID: 31920657; PubMed Central PMCID: PMCPMC6923272

Lv, G., Gu, H., Chen, S., Lou, Z., and Shan, L. (2011). Pharmacokinetic Profile of 2,3,5, $4^{\prime}$-Tetrahydroxystilbene-2-O- $\beta$-D-Glucoside in Mice after Oral Administration of Polygonum Multiflorumextract. Drug Dev. Ind. Pharm. 38 (2), 248-255. doi:10.3109/03639045.2011.597763

Lv, G., Lou, Z., Chen, S., Gu, H., and Shan, L. (2011). Pharmacokinetics and Tissue Distribution of 2,3,5,4'-Tetrahydroxystilbene-2-O- $\beta$-D-Glucoside from Traditional Chinese Medicine Polygonum Multiflorum Following Oral Administration to Rats. J. Ethnopharmacology 137 (1), 449-456. doi:10.1016/j.jep.2011.05.049Epub 2011/06/18PubMed PMID: 21679759

Ma, J., Zheng, L., He, Y.-S., and Li, H.-J. (2015). Hepatotoxic Assessment of Polygoni Multiflori Radix Extract and Toxicokinetic Study of Stilbene Glucoside and Anthraquinones in Rats. J. Ethnopharmacology 162, 61-68. doi:10.1016/j.jep.2014.12.045

Ma, N. H., Chen, Y., Xu, C. S., Ding, Y., and Zhang, T. (2020). R[Research Progress of Liver Injury Induced by Polygoni Mulitiflori Radix]Radix. Zhongguo Zhong Yao Za Zhi 45 (15), 3594-3602. doi:10.19540/j.cnki.cjcmm.20200512.30110. 19540/j.cnki.cjcmm.20200512.301

Medicine SAoTC (1999). Chinese Materia Medica. Shanghai.

Crawford, M. J., Ransil, B. J., Narciso, J. P., Gollan, J. L., and Gollan, JL. (1992). Hepatic Microsomal Bilirubin UDP-Glucuronosyltransferase. The Kinetics of Bilirubin Mono- and Diglucuronide Synthesis. J. Biol. Chem. 267 (24), $16943-16950$.

Nies, A. T., Herrmann, E., Brom, M., and Keppler, D. (2008). Vectorial Transport of the Plant Alkaloid Berberine by Double-Transfected Cells Expressing the Human Organic Cation Transporter 1 (OCT1, SLC22A1) and the Efflux Pump MDR1 P-Glycoprotein (ABCB1). Naunyn-schmied Arch. Pharmacol. 376 (6), 449-461. doi:10.1007/s00210-007-0219-xEpub 2007/12/25PubMed PMID: 18157518

Otsuka, M., Matsumoto, T., Morimoto, R., Arioka, S., Omote, H., and Moriyama, Y. (2005). A Human Transporter Protein that Mediates the Final Excretion Step for Toxic Organic Cations. Proc. Natl. Acad. Sci. 102 (50), 17923-17928 -8. doi:10.1073pnas.050648310210.1073/pnas.0506483102

Qi, W., Ya-dan, W., Hai-ruo, W., and Shuang-cheng, M. (2019). Study onToxic Effects of Cis(trans)-2, 3, 5, 4'-Tetrahydroxystilbene-2-O- $\beta$-Dglucoside in Polygonum multiflorumBased on Inhibition of UGT1A1 Enzyme in Rat Liver Microsomes. Mod. Chin. Med. 21 (03), 291-295+302. doi:10.13313/j. issn.1673-4890.20180710004

Qi, W., Zhong, D., Yu-jie, Z., and Shuang-cheng, M. (2015). The Investigation of Kenitics of UGT1A1 Enzyme in Different System on the Basic of Bilirubin Metabolites. Chin. Pharm. J. 50 (19), 1709-1714. doi:10.11669/cpj.2015.19.012 Sasaki, T., Ohta, S., Kamogawa, A., and Shinoda, M. (1990). Protective Effects of Various Chinese Traditional Medicines against Experimental Cholestasis. Chem. Pharm. Bull. 38 (2), 513-516. doi:10.1248/cpb.38.513PubMed PMID: MEDLINE:2337968

Shuwen, Y., and Zhen, C. (2019). Research Progress of Themodel and Signaling Pathways of Acute Liver Injury. J. Pharm. Res. 38 (1), 49-52. doi:10.13506/j. cnki.jpr.2019.01.013

Sun, J. (2004). Studies on the Separation of Stilbene Glycoside from Radix Polygoni Multiflori and its Pharmacokinetics. Shijiazhuang: Hebei medical university.

Wang, Q., Wang, Y., Li, Y., Wen, B., Dai, Z., Ma, S., et al. (2017). Identification and Characterization of the Structure-Activity Relationships Involved in UGT1A1 Inhibition by Anthraquinone and Dianthrone Constituents of Polygonum 
Multiflorum. Sci. Rep. 7 (1), 17952. doi:10.1038/s41598-017-18231-yEpub 2017/12/22PubMed PMID: 29263357; PubMed Central PMCID: PMCPMC5738440

Wang, Y., Wang, L., Saxena, R., Wee, A., Yang, R., Tian, Q., et al. (2019). Clinicopathological Features of $\mathrm{He}$ Shou Wu-induced Liver Injury: This Ancient Anti-aging Therapy Is Not Liver-Friendly. Liver Int. 39 (2), 389-400. doi:10.1111/liv.13939Epub 2018/08/02PubMed PMID: 30066422

Xiaohui, X., Jiangling, Y., Lei, X., Yong, D., and Xiaofeng, L. (2018). Comparison of Histopathological Traits of Five Animal Models of Acute Hepatic Inj Ury. BullDisControlPre 33 (1), 12-15. doi:10.13215/j.cnki.jbytkztb.1710003

Yamakawa, Y., Doi, T., Naitou, Y., Kawai, H., Mitsumoto, A., Kudo, N., et al. (2020). A Single Pretreatment with Clofibric Acid Attenuates Carbon TetrachlorideInduced Necrosis, but Not Steatosis, in Rat Liver. Food Chem. Toxicol. 145, 111591. doi:10.1016/j.fct.2020.111591Epub 2020/08/03PubMed PMID: 32739454

Yang, L., Xiong, A., He, Y., Wang, Z., Wang, C., Wang, Z., et al. (2008). Bile Acids Metabonomic Study on the CCl4- and a-Naphthylisothiocyanate-Induced Animal Models: Quantitative Analysis of 22 Bile Acids by Ultraperformance Liquid Chromatography-Mass Spectrometry. Chem. Res. Toxicol. 21 (12), 2280-2288. doi:10.1021/tx800225qPubMed PMID: WOS:000261736700008

Yi, Y.-X., Ding, Y., Zhang, Y., Ma, N.-H., Shi, F., Kang, P., et al. (2018). Yinchenhao Decoction Ameliorates Alpha-Naphthylisothiocyanate Induced Intrahepatic Cholestasis in Rats by Regulating Phase II Metabolic Enzymes and Transporters. Front. Pharmacol. 9, 510. doi:10.3389/fphar.2018.00510Epub 2018/06/06PubMed PMID: 29867509; PubMed Central PMCID: PMCPMC5962729

Yuan, J., Wei, F., Luo, X., Zhang, M., Qiao, R., Zhong, M., et al. (2020). MultiComponent Comparative Pharmacokinetics in Rats after Oral Administration of Fructus Aurantii Extract, Naringin, Neohesperidin, and NaringinNeohesperidin. Front. Pharmacol. 11, 933, 2020 (Epub 2020/07/09. doi: 10.3389/fphar.2020.00933. PubMed PMID: 32636752; PubMed Central PMCID: PMCPMC7319089

Zhang, J., Wang, T., Ren, Z., Gong, L., Huang, J., Bai, J., et al. (2018). Application of HPLC-LTQ Orbitrap MS for Metabolic Profiles ofPolygonum Multifloraextract in Rats. Biomed. Chromatogr. 32 (2), e4067. doi:10.1002/bmc.4067Epub 2017/ 08/24PubMed PMID: 28833268
Zhang, L., Yang, X., and Deng, Y. (2009). Evaluation and Consideration of Foreign Safety Information of Polygonum Multiflorum Thunb and its Preparations. China J. Chin. Materia Med. 34 (18), 2414-2418.

Zhang, L., Ma, W.-f., Li, J., He, J., Zhang, P., Zheng, F., et al. (2013). Influence of Processing on Pharmacokinetic of Typical Constituents in Radix Polygoni Multiflori after Oral Administration by LC-ESI-MS/MS. J. Ethnopharmacology 148 (1), 246-253. doi:10.1016/j.jep.2013.04.020Epub 2013/04/24PubMed PMID: 23608243

Zhang, M., Lin, L., Lin, H., Qu, C., Yan, L., and Ni, J. (2018). Interpretation the Hepatotoxicity Based on Pharmacokinetics Investigated through Oral Administrated Different Extraction Parts of Polygonum Multiflorum on Rats. Front. Pharmacol. 9, 505. doi:10.3389/fphar.2018.00505Epub 2018/06/ 12PubMed PMID: 29887801; PubMed Central PMCID: PMCPMC5980962

Zhao, M. J., Gong, X. H., Dang, J., Yuan, A., Li, Y., Lou, L., et al. (2017). [Effect of Processing Time of Polygoni Multiflori Radix on Content Changes of 16 Componens]. Zhongguo Zhong Yao Za Zhi 42 (7), 1344-1349. doi:10. 19540/j.cnki.cjcmm.20170121.030Epub 2017/10/21PubMed PMID: 29052397

Zhao, Y., Zhai, D., Chen, X., Yang, J., Song, X., He, H., et al. (2007). Ketoprofen Glucuronidation and Bile Excretion in Carbon Tetrachloride and AlphaNaphthylisothiocyanate Induced Hepatic Injury Rats. Toxicology 230 (2-3), 145-150. doi:10.1016/j.tox.2006.11.008Epub 2006/12/23PubMed PMID: 17184895

Conflict of Interest: The authors declare that the research was conducted in the absence of any commercial or financial relationships that could be construed as a potential conflict of interest.

Copyright (c) $2021 \mathrm{Ma}$, Zhang, Sun, Zhao, Ding and Zhang. This is an open-access article distributed under the terms of the Creative Commons Attribution License (CC $B Y)$. The use, distribution or reproduction in other forums is permitted, provided the original author(s) and the copyright owner(s) are credited and that the original publication in this journal is cited, in accordance with accepted academic practice. No use, distribution or reproduction is permitted which does not comply with these terms. 